\title{
High-Valent Transition-Metal Alkylidene Complexes: Effect of Ligand and Substituent Modification
}

\author{
Thomas R. Cundari ${ }^{\dagger}$ and Mark S. Gordon* \\ Contribution from the Department of Chemistry, North Dakota State University, \\ Fargo, North Dakota 58105-5516. Received June 21, 1991
}

\begin{abstract}
An ab initio investigation into the effects of ligand and substituent modification on the metal-carbon double bond is reported. Prototypical group IVB (Ti, $\mathrm{Zr}, \mathrm{Hf}$ ) and Group VB (Nb, Ta) alkylidenes are chosen for this study. The MC/LMO/CI (multiconfiguration/localized molecular orbital/configuration interaction) procedure is used to examine the electronic structures of these complexes in terms of the prime resonance contributors to the ground-state wave function. The main conclusion drawn from this work is that the intrinsic nature of the metal-carbon double bond can typically be changed only within certain limits by modification of the electronegativity of the ligands $(\mathrm{L})$ and substituents $(\mathrm{Z})$. In other words, the $\mathrm{Ta}=\mathrm{C}$ bond in $\mathrm{H}_{3} \mathrm{TaCH}_{2}$ is very similar to that in $\mathrm{H}_{3} \mathrm{TaCCl}_{2}$ and $\mathrm{Cl}_{3} \mathrm{TaCH}_{2}$ and presumably in experimentally characterized analogues with larger ligands and substituents, e.g., $\mathrm{Cp}$ and neopentyl. Significant changes in the electronic structure are effected in three ways: The first way is through the introduction of a highly electropositive substituent, e.g., Li. This makes the metal-carbon bond closer to a triple bond for the Ta-alkylidenes. The second way to change the electronic structure of the alkylidenes significantly is to change the central metal atom. The heaviest members of groups IVB (Hf) and VB (Ta) are the most nucleophilic at the $\alpha$-carbon. The third way in which the metal-carbon bond could be significantly altered is through the use of $\pi$-donor substituents. The introduction of $\pi$-donor substituents on $\mathrm{C}_{\alpha}$ increases the electrophilicity of the $\alpha$-carbon.
\end{abstract}

\section{Introduction}

Chemists are able to exert a profound influence on the structure and reactivity of transition-metal and organometallic complexes through modification of the ligand environment. ${ }^{1}$ Alkylidene complexes, or Schrock-type carbenes, are no exception to this generalization. Alkylidenes are complexes of the general form $\mathrm{L}_{n} M=\mathrm{C}(\mathrm{R}) \mathrm{R}^{\prime}$, where $\mathrm{R}$ and $\mathrm{R}^{\prime}$ are typically $\mathrm{H}$, alkyl, or silyl. ${ }^{2}$ A good deal of discussion concerning the reactivity of the alkylidenes in important reactions (e.g., olefin metathesis and polymerization, the olefination of carbonyls, etc.) has been presented in terms of the prime resonance contributors which describe the metal-carbon double bond. ${ }^{3}$ The metal-carbon linkage has been described as ethylene-like (IX and XI); ${ }^{3 \mathrm{a}, \mathrm{b}}$ as $\pi$ ylide-like (III); as a dative carbon to metal $\sigma$ bond coupled with a dative metal to carbon $\pi$ back-bond $(\mathrm{XV}) ;^{33, b}$ and as a four-electron donor $(\mathrm{I}) .^{3 \mathrm{~b}}$

$$
\begin{aligned}
& M \frac{\pi}{\sigma} \mathrm{C} \quad M \stackrel{\pi}{\frac{\pi}{\sigma}} \mathrm{C} \quad M \stackrel{\pi}{\underset{\sigma}{\sigma}} \mathrm{C} \quad M \stackrel{\pi}{\frac{\pi}{\sigma}} \mathrm{C} \quad M \frac{\pi}{\sigma} \mathrm{C} \\
& \mathrm{IX}, \mathrm{XI} \quad \mathrm{III} \quad \mathrm{XV} \quad \text { I } \quad \text { VII }
\end{aligned}
$$

(Resonance structures are numbered to agree with those given in the tables; vide infra. The convention of straight lines and arrows representing covalent and dative bonds, respectively, has been used.) In an earlier study, the MC/LMO/CI (multiconfiguration/localized molecular orbital/configuration interaction) procedure was applied to high-valent, alkylidene complexes ${ }^{4}$ of the form $\mathrm{L}_{n} M\left(\mathrm{CH}_{2}\right)$, i.e., methylidene complexes, where $\mathrm{L}_{n}$ is typically comprised of hydrogen atoms. The $\mathrm{MC} / \mathrm{LMO} / \mathrm{CI}$ procedure allows one to deduce a more quantitative measure of the contributions made by resonance structures like those shown above. The most interesting result is that a heretofore unconsidered resonance structure, VII (termed the $\sigma$ ylide), was a prime resonance contributor $(\approx 33 \%)$ along with $\mathrm{IX}$ and $\mathrm{XI}(\approx 33 \%)$, III $(\approx 12 \%), X V(\approx 8 \%)$, and I $(\approx 6 \%)$ in the methylidene complexes. $^{4 a}$

The $\mathrm{H}$ atom approximately simulates the electronic demands of an alkyl group, on either the metal or the carbene carbon. More (or less) electron-withdrawing ligands (e.g., $\mathrm{Cp}$ or $\mathrm{Cl}$ ) are expected to change the electronic structure of the alkylidene. The chemistry of the alkylidene may also be altered by modification of the substituents ( $\left.R, R^{\prime}\right)$ on the alkylidene. To what extent these replacements modify the intrinsic nature of the metal-carbon double bond is the topic with which this paper is primarily concerned.

${ }^{\dagger}$ Present address: Department of Chemistry, Memphis State University, Memphis, TN 38152
In the present paper the effects of ligand and alkylidene substitution on the nature of the metal-carbon double bond of prototypical Schrock-type carbenes are probed. Two sets of alkylidenes, from group IVB ( $\mathrm{Ti}, \mathrm{Zr}, \mathrm{Hf}$ ) and group VB (Nb, Ta), are chosen for this study. ${ }^{5}$ The group IVB alkylidenes are important due to their putative intermediacy in olefin polymerization and metathesis, etc., but their extreme has resulted in limited structural information. ${ }^{6}$ Group IVB alkylidenes have been isolated as adducts of olefins (e.g., titanacyclobutanes ${ }^{6 a}$ ) and organoaluminum

(1) A cursory glance at any advanced inorganic (Wilkinson, G.; Cotton F. A. Advanced Inorganic Chemistry, 5th ed.; Wiley: New York, 1988) or organometallic (Comprehensive Organometallic Chemistry; Wilkinson, G. Stone, F. G. A., Abel, E. W., Eds.; Pergamon: Oxford, 1982) text should convince the reader as to this point.

(2) (a) Schrock, R. R. J. Organomet. Chem. 1986, 300, 249. (b) Schrock, R. R. Acc. Chem. Res. 1990, 23, 158. (c) Schrock, R. R. Acc. Chem. Res. 1979, 12, 98. (d) Mayer, J. M.; Nugent, W. A. Metal-Ligand Multiple Bonds; Wiley: New York, 1989

(3) (a) Hall, M. B.; Taylor, T. E. J. Am. Chem. Soc. 1984, 106, 1576. (b) Collmann, J. P.; Hegedus, L. S.; Norton, J. R.; Finke, R. G. Principles and Applications of Organotransition Metal Chemistry; University Science Books: Mill Valley, 1987. (c) Schrock, R. R. J. Am. Chem. Soc. 1976, 98, 5399. (d) Casey, C. P.; Polichowski, S. W. J. Am. Chem. Soc. 1977, 99, 6097. Casey, C. P.; Tuinstra, H. J. J. Am. Chem. Soc. 1978, 100, 2270. (e) Gassman, P.; Johnson, T. J. J. Am. Chem. Soc. 1977, 99, 622. (f) Brookhart, M.; Studabaker, W. B. Chem. Rev. 1987, 87, 411, Brookhart, M.: Humphrey, M. B. Kratzer, H. J.; Nelson, G. O. J. Am. Chem. Soc. 1980, 102, 7802. (g) Ardill, H. E.; Greene, R. M. E.; Hamilton, J. G.; Ho, H. T.; Ivin, K. J.; Lapienis, G.; McCann, G. M.; Rooney, J. J. In Ring Opening Polymerization; McGrath, J. E. Ed.; Americal Chemical Society: Washington, DC, 1985; p 285.

(4) (a) The application of the MC/LMO/CI procedure to the bonding in simple methylidene complexes is presented in: Cundari, T. R.; Gordon, M. S. J. Am. Chem. Soc. 1991, 113,5231. (b) Ruedenberg and Schmidt tb have implemented a similar scheme in the study of main-group complexes. Ruedenberg, K.; Schmidt, M. W.; Dombek, M. M.; Elbert, S. T. Chem. Phys. 1982, 71, 41, 51, 65. Lam, B.; Schmidt, M. W.; Ruedenberg, K. J. Phys. Chem. 1985, 89, 2221.

(5) An in-depth discussion of the electronic structures of olefin metathesis catalyst models, $\mathrm{M}(\mathrm{L})_{2}(\mathrm{X})(\mathrm{C}(\mathrm{H}) \mathrm{R})$, where $\mathrm{M}=\mathrm{Mo} ; \mathrm{L}=\mathrm{OH}, \mathrm{Cl} ; \mathrm{X}=\mathrm{NH}$, $\mathrm{O} ; \mathrm{R}=\mathrm{H}, \mathrm{Me}, \mathrm{SiH}_{3}, \mathrm{~F} / \mathrm{M}=\mathrm{W} ; \mathrm{L}=\mathrm{OH}, \mathrm{Cl} ; \mathrm{X}=\mathrm{NH}, \mathrm{O} ; \mathrm{R}=\mathrm{H} / \mathrm{M}=$ $\mathrm{Re} ; \mathrm{L}=\mathrm{OH}, \mathrm{Cl} ; \mathrm{X}=\mathrm{CH}, \mathrm{N} ; \mathrm{R}=\mathrm{H}$, is presented elsewhere as they are too large to be treated with the $\mathrm{MC} / \mathrm{LMO} / \mathrm{CI}$ method and other theoretical tool must be used to analyze their bonding. Cundari T. R.; Gordon, M. S. Organometallics, accepted for publication.

(6) (a) Grubbs, R. H.; Mackenzie, P. B.; Ott, K. C. Pure Appl. Chem 1984, 56, 59. Brown-Wensley, K. A.; Buchwald, S. L.; Cannizzo, L.; Clawson. L.; Ho, S.; Meinhart, D.; Stille, J. R.; Straus, D.; Grubbs, R. H. Pure Appl. Chem. 1983, 55, 1733. (b) Tebbe, F. N.; Parshall, G. W.; Reddy, G. S. J. Am. Chem. Soc. 1978, 100, 3611. Tebbe, F. N.; Parshall, G. W.; Ovenall, D. W. J. Am. Chem. Soc. 1979, 101, 5074. Pine, S. H.; Zahler, R.; Evans, D. A.; Grubbs, R. H. J. Am. Chem. Soc. 1980, 102, 3270. (c) Schwartz, J. Clift, S. M. J. Am. Chem. Soc. 1984, 106, 8300. Schwartz, J.; Hartner, F W.; Clift, S. M. J. Am. Chem. Soc. 1983, I05, 640. 


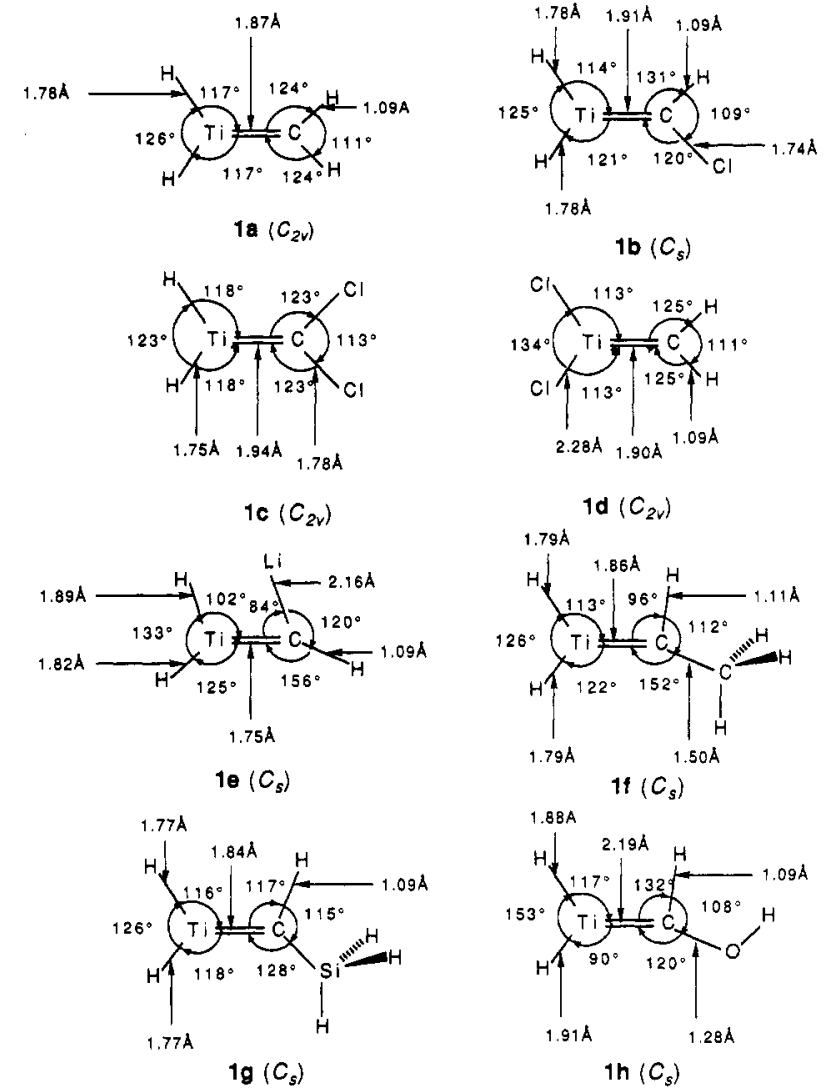

Figure 1. Calculated bond lengths $(\AA)$ and bond angles (deg) for the Ti-alkylidene minima.

compounds (e.g., the Tebbe reagent ${ }^{6 b}$ ); their solution-phase reactivity is indicative of an equilibrium between the adduct and a titanium alkylidene, with the latter being the active species. The group VB complexes are of particular interest since they are related to the earliest high-valent, alkylidenes to have been synthesized, $\mathrm{R}_{3} \mathrm{Ta}=\mathrm{C}(\mathrm{H}) \mathrm{R}^{7 \mathrm{a}}$ In contrast to its heavier congeners, only a few vanadium alkylidene complexes have been reported. ${ }^{8}$ Most of the vanadium alkylidenes which have been characterized have the vanadium in a low oxidation state and thus more closely resemble "Fischer-type" carbenes. Tantalum alkylidenes are ideally suited to the present study since there is a larger amount of experimental information available, and greater attention will be focused on them. ${ }^{2 \mathrm{c}, 7}$

\section{Calculations}

The GAMESS ab initio quantum chemistry program package ${ }^{9}$ is used for all the calculations described herein. The basis set used is that

(7) (a) Schrock, R. R. J. Am. Chem. Soc. 1974, 96. 6796. (b) Schrock, R. R.; Schultz, A. J.; Williams, J. M.; Brown, R. K. J. Am. Chem. Soc. 1981, 103, 169. (c) Schrock, R. R.; Guggenberger, L. J. J. Am. Chem. Soc. 1975, 97, 2935. (d) Wood, C. D.; McClain, S. J.; Schrock, R. R. J. Am. Chem. Soc. 1979, 101, 3210. (e) Schrock, R. R. J. Am. Chem. Soc. 1975, 97, 6577. (f) Schrock, R. R. J. Am. Chem. Soc. 1975, 97, 6578. (g) Wood, C. D.; McLain, S. J.; Schrock, R. R. J. Am. Chem. Soc. 1977, 99, 3519. (h) Schrock, R. R.; Sharp, P. R. J. Am. Chem. Soc. 1978, 100, 2389. (i) Fellmann, J. D.; Schrock, R. R. J. Am. Chem. Soc, 1978, 100, 3359. (j) Wood, C. D.: McLain, S. J.; Schrock, R. R. J. Am. Chem. Soc. 1979, 10I, 3210. (k) Schrock, R. R.; Fellmann, J. D.; Ruprecht, G. A. J. Am. Chem. Soc. 1979, 101, 5099. (1) Schrock, R. R.; Fellmann, J. D.; Ruprecht, G. A. J. Am. Chem. Soc. 1981, 103, 5752. (m) Wallace, K. C.; Dewan, J. C.: Schrock, R. R. Organometallics 1986, 5, 2162. (n) Wallace, K. C.: Schrock, R. R. Macromolecules 1987, 20, 448.

(8) (a) Tueben, J.; Hessen, B.; Meetsma, A. J. Am. Chem. Soc. 1989, 1/l, 5977. (b) Martin, J.: Moise, C.: Tirouflet, J. C. R. Hebd. Seances Acad. Sci. Ser. 2 1981, 292, 1143. (c) Erker, G.; Lecht, R.; Schlund, R.; Angermund, K.; Krüger, C. Angew. Chem., Int. Ed. Eng. 1987, 26, 666. (d) Gas-phase V-alkylidenes; Aristov, N.; Armentrout, P. B. J. Am. Chem. Soc. 1986, 108, 1806.

(9) GAMESS (General Atomic and Molecular Electronic Structure System): Schmidt, M. W.; Baldridge, K. K.; Boatz, J. A.; Jensen, J. H.; Koseki, S.; Gordon, M. S.; Nguyen, K. A.; Windus, T. L.; Elbert, S. T. QCPE Bull. 1990, 10,52 .
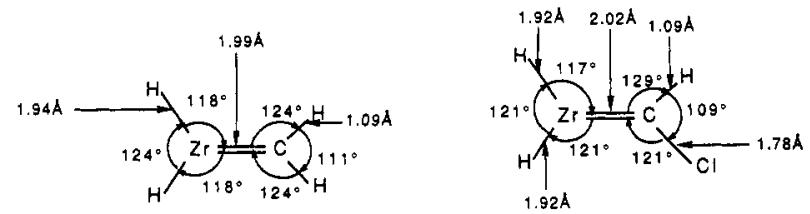

2a $\left(C_{2 v}\right)$
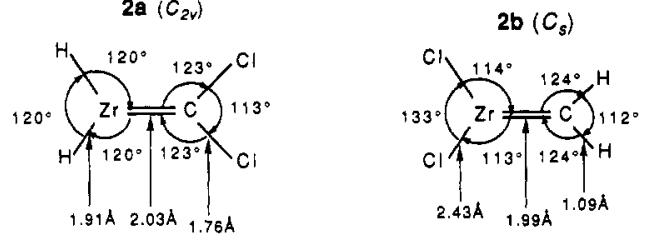

$2 \mathrm{c}\left(C_{2 v}\right)$

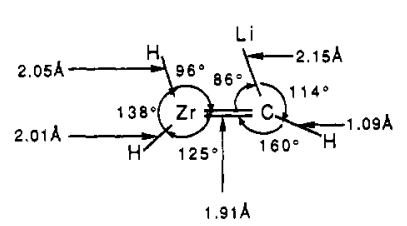

$2 e\left(C_{s}\right)$

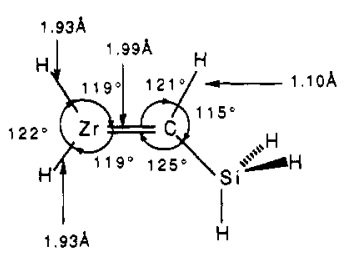

$2 \mathrm{~g}\left(C_{s}\right)$

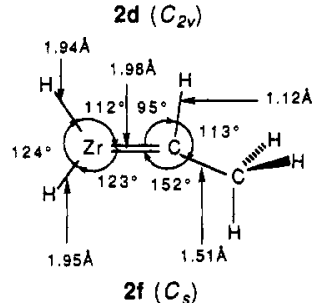

$2 f\left(C_{s}\right)$

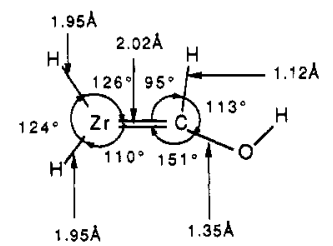

$2 \mathrm{~h}\left(C_{s}\right)$

Figure 2. Calculated bond lengths $(\AA)$ and bond angles (deg) for the Zr-alkylidene minima.

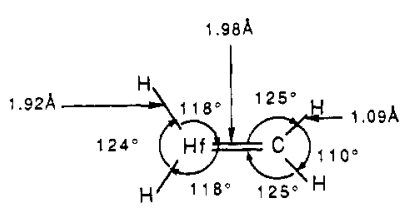

$3 a\left(C_{2 v}\right)$

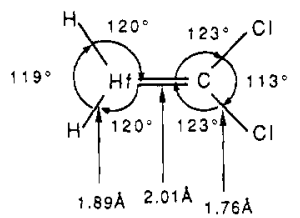

$3 \mathrm{c}\left(C_{2 v}\right)$

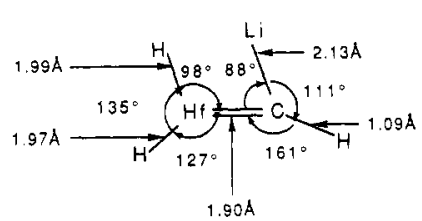

$3 \mathrm{e}\left(C_{s}\right)$

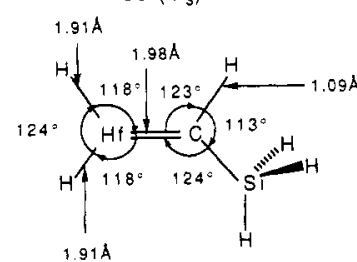

$3 \mathrm{~g}\left(C_{s}\right)$

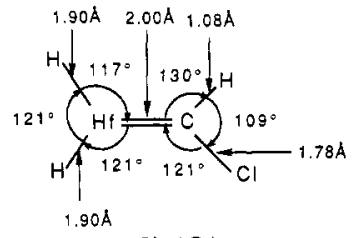

3b $\left(C_{s}\right)$

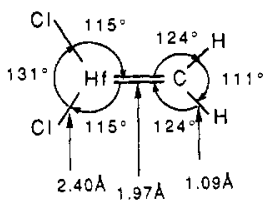

$3 d\left(C_{2 v}\right)$

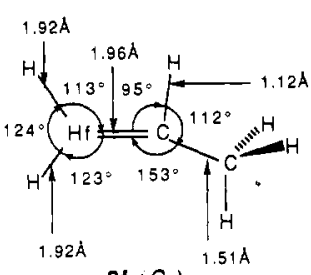

$3 f\left(C_{s}\right)$

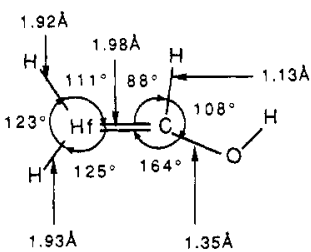

3h $\left(C_{s}\right)$

Figure 3. Calculated bond lengths $(\AA)$ and bond angles (deg) for the Hf-alkylidene minima.

previously referred to as basis B. ${ }^{4 a}$ Basis B entails the use of the Stevens, Basch, Krauss, Jasien (SBKJ) effective core potentials (ECPs) ${ }^{10}$ and 
Table I. Calculated $\mathrm{M}=\mathrm{C}_{\alpha}$ and $\mathrm{C}-\mathrm{H}_{\alpha}$ Stretching Frequencies and Force Constants for Group IVB Alkylidenes ${ }^{a}$

\begin{tabular}{|c|c|c|c|c|c|c|}
\hline & \multicolumn{2}{|c|}{ Ti-alkylidenes } & \multicolumn{2}{|c|}{$\mathrm{Zr}$-alkylidenes } & \multicolumn{2}{|c|}{ Hf-alkylidenes } \\
\hline & $\nu_{\mathrm{CH}_{\alpha}}\left(k_{\mathrm{CH}_{\alpha}}\right)$ & $\nu_{\mathrm{TiC}_{\alpha}}\left(k_{\mathrm{TiC}_{\alpha}}\right)$ & $\nu_{\mathrm{H}_{\alpha}}\left(k_{\mathrm{CH}_{\alpha}}\right)$ & $\nu_{\mathrm{Zr}_{\alpha}}\left(k_{\mathrm{ZrC}_{\alpha}}\right)$ & $\nu_{\mathrm{CH}_{\alpha}}\left(k_{\mathrm{CH}_{\alpha}}\right)$ & $\nu_{\mathrm{HfC}_{\alpha}}\left(k_{\mathrm{HfC}_{\alpha}}\right)$ \\
\hline $\begin{array}{l}\mathrm{H}_{2} \mathrm{M}=\mathrm{CH}_{2} \\
\mathrm{H}_{2} \mathrm{M}=\mathrm{C}(\mathrm{H}) \mathrm{Cl} \\
\mathrm{H}_{2} \mathrm{M}=\mathrm{Cl}_{2} \\
\mathrm{Cl}_{2} \mathrm{M}=\mathrm{C} \mathrm{CH}_{2} \\
\mathrm{H}_{2} \mathrm{M}=\mathrm{C}(\mathrm{H}) \mathrm{Li} \\
\mathrm{H}_{2} \mathrm{M}=\mathrm{C}(\mathrm{H}) \mathrm{Me} \\
\mathrm{H}_{2} \mathrm{M}-\mathrm{C}(\mathrm{H}) \mathrm{SiH}_{3} \\
\mathrm{H}_{2} \mathrm{M}=\mathrm{C}(\mathrm{H}) \mathrm{OH}\end{array}$ & $\begin{array}{l}3250(5.8) \\
3249(5.8) \\
\\
3262(5.8) \\
3260(5.8) \\
3010(5.0) \\
3189(5.6) \\
3211(5.6)\end{array}$ & $\begin{array}{l}738(3.1) \\
669(2.5) \\
623(2.2) \\
657(2.4) \\
950(5.1) \\
715(2.9) \\
784(3.5) \\
363(0.7)\end{array}$ & $\begin{array}{l}3231(5.7) \\
3275(5.9) \\
\\
3243(5.8) \\
3246(5.8) \\
2931(4.7) \\
3175(5.5) \\
2890(4.6)\end{array}$ & $\begin{array}{l}775(3.8) \\
765(3.6) \\
748(3.5) \\
773(3.7) \\
901(5.1) \\
791(3.9) \\
784(3.8) \\
674(2.8)\end{array}$ & $\begin{array}{l}3228(5.7) \\
3289(5.9) \\
\\
3241(5.8) \\
3261(5.8) \\
2906(4.6) \\
3187(5.6) \\
2857(4.5)\end{array}$ & $\begin{array}{l}788(4.1) \\
787(4.1) \\
779(4.0) \\
796(4.2) \\
912(5.5) \\
818(4.4) \\
792(4.2) \\
746(3.7)\end{array}$ \\
\hline
\end{tabular}

${ }^{a}$ Stretching frequencies are reported in $\mathrm{cm}^{-1}$; force constants (in parentheses) are reported in mdyn $\AA^{-1}$ for the minima displayed in Figures $1-3$. These frequencies and force constants were calculated using the methods detailed in: Boatz, J. A.; Gordon, M. S. J. Phys. Chem. $1989,93,1819$.

valence basis for the transition metals and third-row main-group elements plus the 3-21G basis for all second-row main-group elements and hydrogen. The basis sets of second- and third-row main-group elements (except $\mathrm{Li}$ ) are augmented with a standard d-polarization function. ${ }^{11}$ This combination of basis sets and ECPs yields excellent agreement between calculated and experimentally determined geometries for model alkylidenes. ${ }^{4 a}$ Other computational details are identical to those described previously. ${ }^{4 a}$ The force constant matrices are calculated in order to establish that calculated stationary points are indeed minima (i.e., all positive force constants) on the potential energy surfaces.

\section{Results and Discussion}

1. Geometries. a. Group IVB Alkylidenes. To more effectively model ligands which are more electron withdrawing than $\mathrm{H}$ or alkyl, e.g., $\mathrm{Cp}$ or $\mathrm{Cl}$, the $\mathrm{H}$ ligand is replaced by the $\mathrm{Cl}$ ligand. Alkylidene substituents range from electronegative $(\mathrm{F}, \mathrm{OH}, \mathrm{Cl})$ to electropositive $\left(\mathrm{Li}, \mathrm{SiH}_{3}\right)$. The calculated geometries of the $\mathrm{Ti}-, \mathrm{Zr}^{-}$, and $\mathrm{Hf}$-alkylidenes as a function of alkylidene substituent $\left(\mathrm{H}, \mathrm{Cl}, \mathrm{Li}, \mathrm{SiH}_{3}, \mathrm{CH}_{3}, \mathrm{OH}\right)$ and metal ligand $(\mathrm{H}, \mathrm{Cl})$ are summarized in Figures 1-3, respectively. A force field analysis establishes all the geometries shown in these figures as minima. The geometries of the analogous $\mathrm{Ti}^{-}, \mathrm{Zr}^{-}$, and $\mathrm{Hf}$-alkylidenes are comparable, with the latter two being the most similar. The metal-carbon bond lengths in the Ti-alkylidenes are shorter by $\approx 0.1 \AA$ when compared to their $\mathrm{Zr}$ and Hf counterparts due to the smaller ionic and covalent radii of $\mathrm{Ti}$. The geometries of the minima are, for the most part, routine. The most noticeable exceptions are the $\mathrm{Li}-$, methyl-, and $\mathrm{OH}$-substituted alkylidenes. In general, the more electropositive alkylidene substituent $(Z)$ subtends an $\mathrm{M}=\mathrm{C}_{\alpha}-Z$ angle which is much less than $120^{\circ}$. As a result one of the other angles about $\mathrm{C}_{\alpha}$ is much larger than $120^{\circ} .12$ This distortion shortens (relative to $\mathrm{H}_{3} \mathrm{MCH}_{2}$ ) the $\mathrm{M}=\mathrm{C}$ bond by $\approx 0.01 \AA$ in the ethylidene complexes. For the lithiomethylidenes there is a pronounced contraction of the $\mathrm{M}=\mathrm{C}$ bond length, $\approx 0.08 \AA$, while for the hydroxymethylidenes the metalcarbon bond lengthens (Table I), especially for $\mathrm{H}_{2} \mathrm{TiC}(\mathrm{H}) \mathrm{OH}$ (1h). The Li subsitutent also causes a lengthening of $\mathrm{M}-\mathrm{H}$, suggesting the possibility of $\mathrm{M} \cdots \mathrm{Li}$ or $\mathrm{H} \cdots \mathrm{Li}$ interaction. The closest $\mathrm{H}$... Li distance in the lithiomethylidenes is approximately $2.0 \AA$; the average M...Li distance is $2.7 \AA$ in these same compounds. In the hydroxymethylidene, $1 \mathrm{~h}, \mathrm{OH}$ seems a special anomaly for $\mathrm{M}=\mathrm{Ti}$, with a very long $\mathrm{Ti}=\mathrm{C}$ bond.

The calculated $\mathrm{M}=\mathrm{C}_{\alpha}$ and $\mathrm{C}_{\alpha}-\mathrm{H}_{\alpha}$ force constants and vibrational frequencies for the group IVB minima are listed in Table I. The $\mathrm{C}_{\alpha}-\mathrm{H}_{\alpha}$ stretching frequencies and force constants are nearly equal for analogous group IVB alklyidenes with the same ligands and substituents. The $\mathrm{M}=\mathrm{C}_{\alpha}$ force constants in Table I follow the general trend $\mathrm{Ti}<\mathrm{Zr}<\mathrm{Hf}$. The trends in metalcarbon force constants are in contrast with the calculated met-

(10) Krauss, M.; Stevens, W. J.; Basch, H.; Jasien, P. G. Can. J. Chem., submitted for publication.

(11) Hehre, W. J.: Radom, L.; Schleyer, P. v. R.: Pople, J. A. Ab-Initio Molecular Orbital Theory; Wiley: New York, 1986; Section 4.3.

(12) Geometric distortions have been observed in high-valent aikylidenes and have received some attention. ${ }^{2,12}$ (a) Rupprecht, G. A.; Messerle, $L$. W.: Fellmann, J. D.; Schrock, R. R. J. Am. Chem. Soc. 1980, 102, 6236. Rocklage, S. M.; Schrock, R. R. J. Am. Chem. Soc. 1980, 102, 7808. (b) Hoffmann, R.; Jemmis, E.; Goddard, R. J. J. Am. Chem. Soc. 1980, 102 , 7667. (c) Francl, M. M.; Pietro, W. J.; Hout, R. F.; Hehre, W. J. Organometallics 1983, 2, 281 .
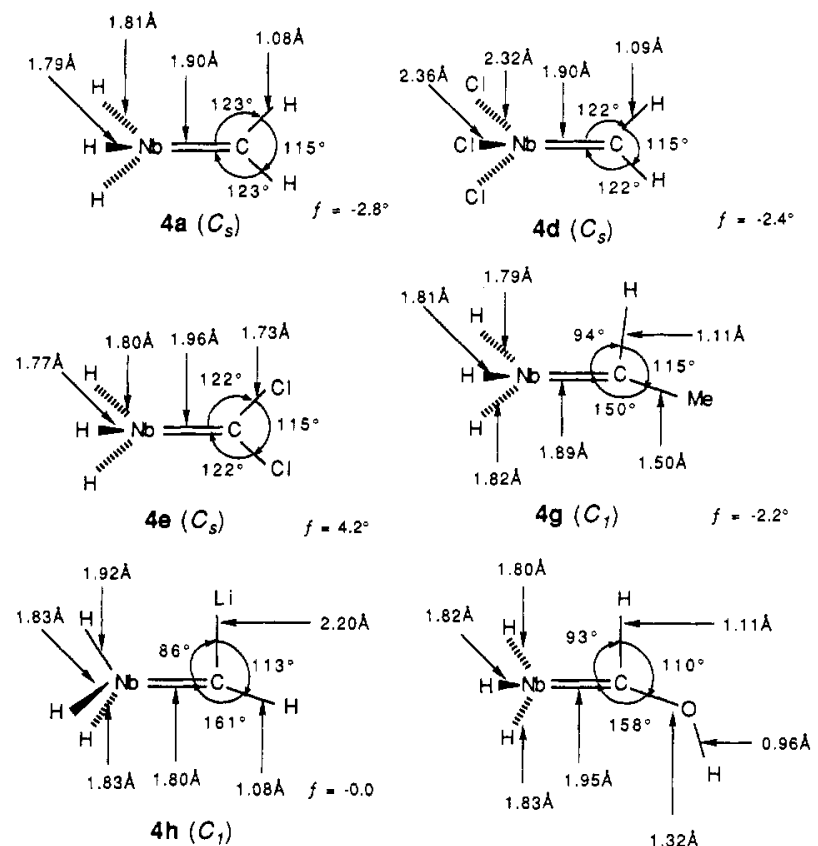

$4 \mathrm{~h}\left(C_{1}\right)$

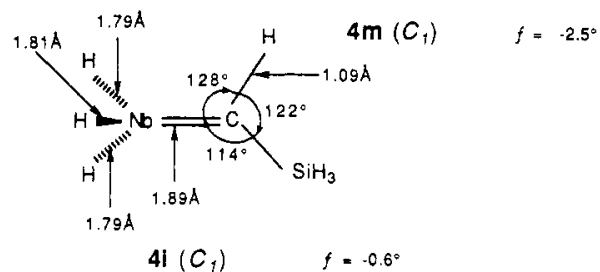

Figure 4. Calculated bond lengths ( $\AA$ ) and bond angles (deg) for the $\mathrm{Nb}$-alkylidene minima.

al-carbon bond lengths. The force constants suggest that the $\mathrm{Zr}-$ and $\mathrm{Hf}$-alkylidenes form stronger metal-carbon bonds despite possessing longer bonds than the Ti analogues. When alkylidenes of the same metal are compared, the usual correlation of longer bonds possessing smaller force constants is found.

b. Group VB Alkylidenes. The geometry-optimized minima for $\mathrm{Nb}-$ and $\mathrm{Ta}$-alkylidenes are displayed in Figures 4 and 5 , respectively. The geometries of those $\mathrm{Nb}$ - and $\mathrm{Ta}$-alkylidenes with the same substituents and ligands are very similar. All attempts at locating V-alkylidene minima were unsuccessful. Transfer of a ligand atom to the carbene $C$, to produce a V-alkyl species, was found in all vanadium geometry optimizations. For example, a geometry optimization of $\mathrm{H}_{3} \mathrm{~V}=\mathrm{CH}_{2}$ results in a minimum with the structural formula $\mathrm{H}_{2} \mathrm{~V}-\mathrm{CH}_{3}$.

A large number of electron-deficient $\mathrm{Ta}$-alkylidenes have been synthesized and characterized by neutron and X-ray diffraction techniques. ${ }^{2 a, c, d, 7} \mathrm{Ta}$-alkylidenes with $\mathrm{Ta}-\mathrm{C}_{\alpha}-\mathrm{H}_{\alpha}$ angles of approximately $90^{\circ}$ have been measured in those complexes which have been studied by neutron diffraction. ${ }^{2 c, 7 b}$ For $\mathrm{H}_{3} \mathrm{MCH}_{2}$ (M $=\mathrm{Nb}, \mathrm{Ta}$ ) starting the geometry optimizations with $\mathrm{M}=\mathrm{C}-\mathrm{H}$ angles of less than $90^{\circ}$ resulted in minima for the methylidene complexes with "normal" coordination (i.e., $\approx 120^{\circ} \mathrm{M}=\mathrm{C}_{\alpha}-\mathrm{H}_{\alpha}$ 


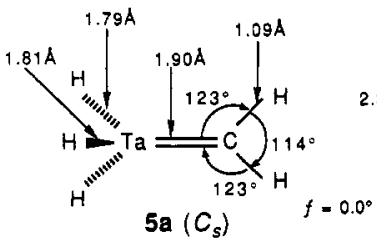

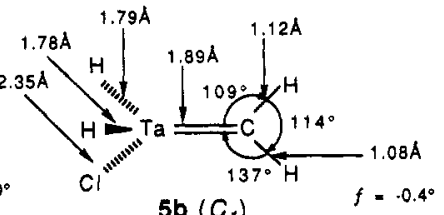

$\mathbf{5 b}\left(C_{1}\right)$
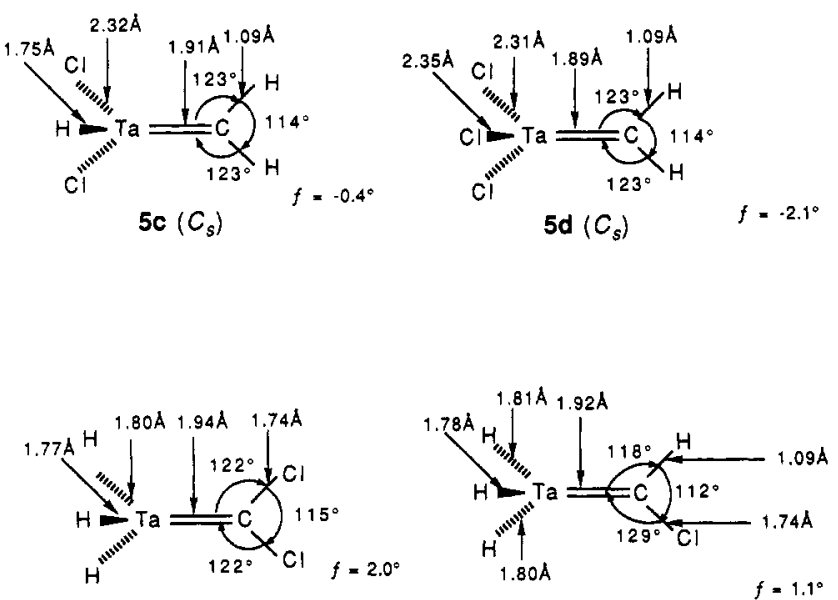

$5 e\left(C_{s}\right)$

$5 f\left(C_{1}\right)$
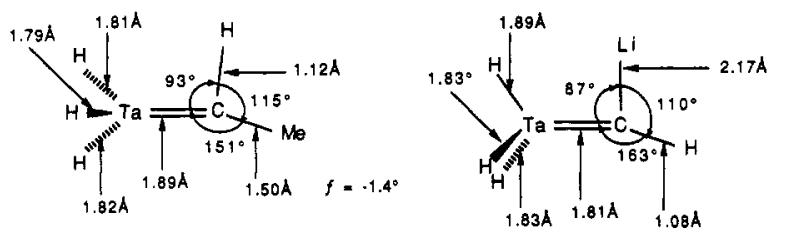

$5 \mathbf{g}\left(C_{1}\right)$

5h $\left(C_{1}\right)$

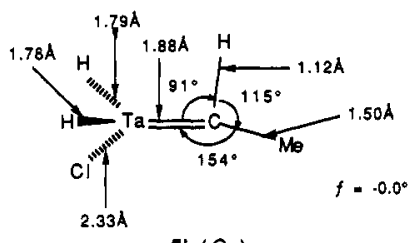

$51\left(C_{1}\right)$

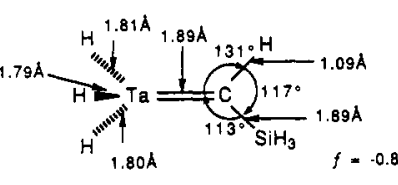

5] $\left(C_{1}\right)$

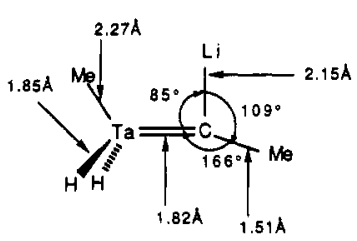

$5 \mathrm{k}\left(C_{s}\right)$

$f=0.0^{\circ}$

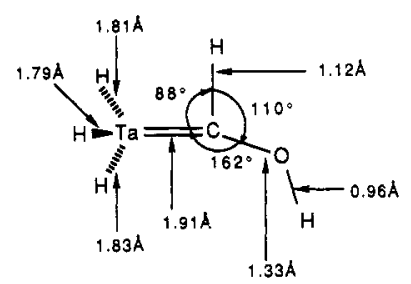

$5 \mathrm{~m}\left(C_{1}\right) \quad f=-0.5^{\circ}$

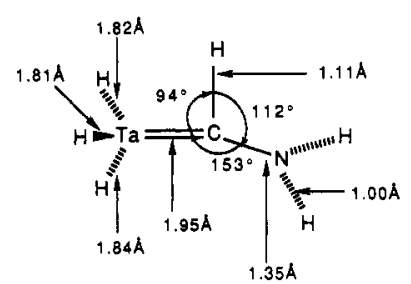

$50\left(C_{1}\right) \quad f=-2.0^{\circ}$

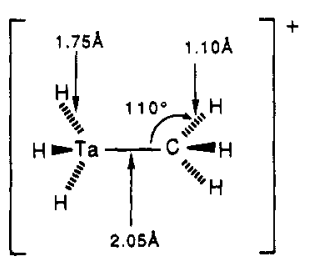

$5 q\left(C_{3 v}\right)$

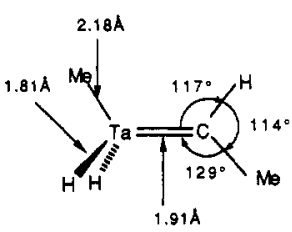

$51\left(C_{s}\right) \quad f=0.0^{\circ}$

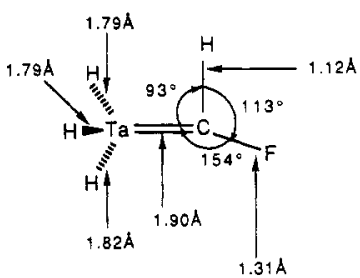

5n $\left\langle C_{1}\right\rangle \quad f=0.0^{\circ}$

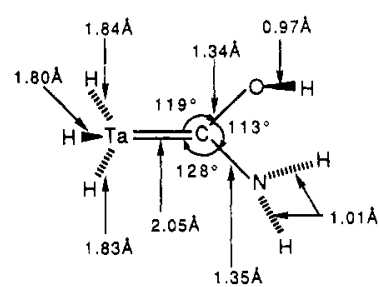

$5 p\left(C_{1}\right) \quad f=-2.0^{\circ}$

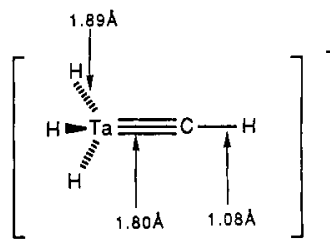

$5 r\left(C_{3 v}\right)$

Figure 5. Calculated bond lengths $(\AA)$ and bond angles (deg) for the Ta-alkylidene minima. 51 is a transition state; see text.

angles and trigonal-planar coordination about the $\alpha$-carbon in $4 \mathrm{a}$ and 5a).

Hoffmann et al. ${ }^{12 b}$ have examined the forces which allow the carbene ligand to assume geometries in which one $\mathrm{M}=\mathrm{C}_{\alpha}-\mathrm{Z}$ angle is significantly less than $120^{\circ}$, while the other angle is significantly greater than $120^{\circ}$ for the model complexes $\mathrm{TaH}_{4}$ $\left(\mathrm{CH}_{2}\right)^{3-}$ and $\mathrm{TaH}_{4}(=\mathrm{C}(\mathrm{H}) \mathrm{Me})^{3-}$. These authors conclude that an interaction between the carbene lone pair and a vacant metal orbital allows the carbene ligand to pivot while still maintaining the metal-carbon $\sigma$ bond. ${ }^{12 b}$ They further conclude that steric requirements play an important role in determining the $\mathrm{M}=\mathrm{C}-\mathrm{H}$ angle. ${ }^{12 \mathrm{~b}}$ This alkylidene distortion has also been ascribed to donation of electron density from the $\mathrm{C}-\mathrm{Z}$ bond to the electrondeficient $\mathrm{Ta}^{7 b}$ For the molecules studied here, evidence in support of $\mathrm{C}-\mathrm{H}$ electron donation comes from a calculation of the $\mathrm{C}_{\alpha}-\mathrm{H}_{\alpha}$ force constant and stretching frequencies, listed in Table II. One would expect that as electron density is removed from the $\mathrm{C}_{\alpha}-\mathrm{H}_{\alpha}$ bond, the stretching frequency $\left(\nu_{\mathrm{CH}}\right)$ will decrease. The $\nu_{\mathrm{CH}}$ for the "nondistorted" Ta-alkylidenes (e.g., 5a-5c and 5i) are roughly $3270 \mathrm{~cm}^{-1}$ (which scales ${ }^{13}$ to $2900 \mathrm{~cm}^{-1}$ ). For "distorted" Ta- alkylidenes (e.g., $5 \mathrm{~g}, 5 \mathbf{5}$, and $5 \mathrm{~m}$ ) the $\mathrm{C}_{\alpha}-\mathrm{H}_{\alpha}$ bonds are significantly weaker $\left(\nu_{\mathrm{CH}} \approx 2935 \mathrm{~cm}^{-1}\right.$, or $2613 \mathrm{~cm}^{-1}$ when scaled). Lower than typical $\mathrm{C}_{\alpha}-\mathrm{H}_{\alpha}$ IR stretching frequencies have been noted for electron-deficient Ta-alkylidenes: $\quad \nu_{\mathrm{CH}}=2605 \mathrm{~cm}^{-1}$ for $\left[\mathrm{TaCl}_{3}\left(\mathrm{PMe}_{3}\right)\left(=\mathrm{C}(\mathrm{H}) \mathrm{CMe}_{3}\right)\right]_{2}$ and $\nu_{\mathrm{CH}}=2510 \mathrm{~cm}^{-1}$ for $\mathrm{TaCpCl}_{2}\left(=\mathrm{C}(\mathrm{H}) \mathrm{CMe}_{3}\right){ }^{2 \mathrm{c}}$ These $\mathrm{C}-\mathrm{H}$ stretching frequencies are in good agreement with the calculated values. $\mathrm{C}-\mathrm{H}$ stretching frequencies for nondistorted, non-electron-deficient alkylidenes are estimated to be in the area of $2900 \mathrm{~cm}^{-1}$. ${ }^{2 \mathrm{~d}, 7 \mathrm{~d}}$ The calculated $\nu_{\mathrm{CH}}$ (scaled) for the "nondistorted" Ta-alkylidenes also support this estimate.

Since the bond between $\mathrm{C}_{\alpha}$ and the more electropositive substituent subtends a smaller angle with the $M=C_{\alpha}$ bond, the

(13) Stretching frequencies calculated at the Hartree-Fock level are of ten multiplied by a scale factor of 0.89 in order to account for electron correlation. Pople, J, A.; Schlegel, H. B.; Krishnan, R.; DeFrees, D. F.; Binkley, J. S.; Frisch, M. J.: Whiteside, R.; Hout, R. F.; Hehre, W. J. Int. J. Quant. Chem., Proc. Sanibel Symp. 1981, 15, 269.

(14) Schubert, U. In Transition Metal Carbene Complexes; Dötz, K. H., Ed.; Verlag: Weinheim, 1983; p 73. 
Table II. Calculated $\mathrm{M}=\mathrm{C}_{\alpha}$ and $\mathrm{C}-\mathrm{H}_{\alpha}$ Stretching Frequencies and Force Constants for Group VB Alkylidenes ${ }^{a}$

\begin{tabular}{|c|c|c|c|}
\hline \multirow[b]{2}{*}{ compound $^{b}$} & \multicolumn{2}{|c|}{$\mathrm{Ta}$-alkylidenes } & \multirow{2}{*}{$\begin{array}{c}\mathrm{Nb} \text {-alkylidenes } \\
\nu_{\mathrm{NbC}_{\alpha}}\left(k_{\mathrm{NbC}_{\alpha}}\right)^{c}\end{array}$} \\
\hline & $\nu_{\mathrm{CH}_{\alpha}}\left(k_{\mathrm{CH}_{\alpha}}\right)$ & $\nu_{\mathrm{TaC}_{\alpha}}\left(k_{\mathrm{TaC}_{\alpha}}\right)$ & \\
\hline $\mathrm{H}_{3} \mathrm{M}=\mathrm{CH}_{2}(4 \mathrm{a}, 5 \mathrm{a})$ & $3248(5.8)$ & $868(5.0)$ & $840(4.4)$ \\
\hline $\mathrm{ClH}_{2} \mathrm{M}=\mathrm{CH}_{2}(\mathbf{5 b})$ & $3163(5.5) ; 3345(6.1)$ & $883(5.2)$ & \\
\hline $\mathrm{Cl}_{2} \mathrm{HM}=\mathrm{CH}_{2}(5 \mathrm{c})$ & $3274(5.9)$ & $861(4.9)$ & \\
\hline $\mathrm{Cl}_{3} \mathrm{M}=\mathrm{CH}_{2}(\mathbf{4 d}, \mathbf{5 d})$ & $3278(5.9)$ & $874(5.1)$ & $824(4.2)$ \\
\hline $\mathrm{H}_{3} \mathrm{M}=\mathrm{CCl}_{2}(4 \mathbf{e}, 5 \mathbf{e})$ & & $826(4.5)$ & $764(3.7)$ \\
\hline $\mathrm{H}_{3} \mathrm{M}=\mathrm{C}(\mathrm{H}) \mathrm{Cl}(\mathbf{5 f})$ & $3267(5.8)$ & $845(4.7)$ & \\
\hline $\mathrm{H}_{3} \mathrm{M}=\mathrm{C}(\mathrm{H}) \mathrm{Me}(\mathbf{4 g}, 5 \mathrm{~g})$ & 2937 (4.7) & $897(5.3)$ & 849 (4.5) \\
\hline $\mathrm{H}_{3} \mathrm{M}=\mathrm{C}(\mathrm{H}) \mathrm{Li}(\mathbf{4 h}, 5 \mathrm{~h})$ & $3317(6.0)$ & $1032(7.1)$ & $1016(6.5)$ \\
\hline $\mathrm{H}_{3} \mathrm{M}=\mathrm{C}(\mathrm{H}) \mathrm{SiH}_{3}(\mathbf{4 i}, \mathbf{5 i})$ & $3272(5.9)$ & $884(5.2)$ & $857(4.6)$ \\
\hline $\mathrm{ClH}_{2} \mathrm{M}=\mathrm{C}(\mathrm{H}) \mathrm{Me}(5 \mathbf{j})$ & $2934(4.7)$ & $904(5.4)$ & \\
\hline $\mathrm{MeH}_{2} \mathrm{M}=\mathrm{C}(\mathrm{Me}) \operatorname{Li}(\mathbf{5} \mathbf{k})$ & & $1013(6.8)$ & \\
\hline $\mathrm{MeH}_{2} \mathrm{M}=\mathrm{C}(\mathrm{H}) \mathrm{Me}(5 \mathrm{l})$ & $3219(5.7)$ & $847(4.8)$ & \\
\hline $\mathrm{H}_{3} \mathrm{M}=\mathrm{C}(\mathrm{H}) \mathrm{OH}(4 \mathrm{~m}, 5 \mathrm{~m})$ & $2872(4.5)$ & $791(4.1)$ & $648(2.6)$ \\
\hline $\mathrm{H}_{3} \mathrm{M}=\mathrm{C}(\mathrm{H}) \mathrm{F}(\mathbf{5 n})$ & $2903(4.6)$ & $854(4.8)$ & \\
\hline $\mathrm{H}_{3} \mathrm{M}=\mathrm{C}(\mathrm{H}) \mathrm{NH}_{2}(\mathbf{5 0})$ & $3033(5.0)$ & $686(3.1)$ & \\
\hline $\mathrm{H}_{3} \mathrm{M}=\mathrm{C}(\mathrm{OH}) \mathrm{NH}_{2}(5 \mathrm{p})$ & & $543(2.0)$ & \\
\hline$\left[\mathrm{H}_{3} \mathrm{M}-\mathrm{CH}_{3}\right]^{+}$ & $3173(5.5)$ & $599(2.4)$ & \\
\hline$\left[\mathrm{H}_{3} \mathrm{M} \equiv \mathrm{CH}\right]^{-}(\mathbf{5 r})$ & $3304(6.0)$ & $1079(7.7)$ & \\
\hline
\end{tabular}

${ }^{a}$ Stretching frequencies are reported in $\mathrm{cm}^{-1}$; force constants (in parentheses) are reported in mdyn $\AA^{-1}$ for group VB alkylidenes. These frequencies and force constants were calculated using the methods detailed in: Boatz, J. A.; Gordon, M. S. J. Phys. Chem. 1989, 93, 1819. ${ }^{b}$ The labels (bold and in parentheses) for each alkylidene correspond to those given in Figures 4 and 5 . ${ }^{c}$ The calculated force constants (mdyn $\AA^{-1}$ ) and stretching frequencies $\left(\mathrm{cm}^{-1}\right)$ for the $\mathrm{Nb}$-alkylidene minima given in Figure 4 are reported. The $\mathrm{C}_{\alpha}-\mathrm{H}_{\alpha}$ values in the $\mathrm{Nb}$-alkylidenes nearly identical to those for the Ta-alkylidenes are not reported.

$\mathrm{M}=\mathrm{C}_{\alpha}-\mathrm{Li}$ and $\mathrm{M}=\mathrm{C}_{\alpha}-\mathrm{Si}$ angles in the lithiomethylidene, $\mathbf{4 h}$ and $\mathbf{5 h}$, and silylmethylidene, $4 \mathbf{i}$ and $\mathbf{5 i}$, complexes, respectively, are smaller than the $\mathrm{M}=\mathrm{C}_{\alpha}-\mathrm{H}_{\alpha}$ angle. That this is the case for the bulky silyl group suggests that the electronic driving force must be quite strong. For the lithiomethylidene the angle is acute and the carbene substituents are not staggered (i) with respect to the ligands (as are all the remaining $\mathrm{Ta}$-alkylidenes with no $\mathrm{Li}$ substituent) but eclipsed (ii). The eclipsed geometry suggests

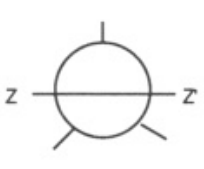

i<smiles>[Z]C1CCC(C)C2([Z])CCCC1C2</smiles>

il a weak electrostatic interaction between the $\mathrm{Li}$ and hydride or methyl ligand closest to it. To further probe the consequences of $\mathrm{Li}$ substitution, a simplified model of the experimentally characterized $\left(\mathrm{Me}_{3} \mathrm{CCH}_{2}\right)_{3} \mathrm{Ta}=\mathrm{C}\left(\mathrm{CMe}_{3}\right) \mathrm{Li}(\mathrm{dmp})$, dmp $=N$,$N^{\prime}$-dimethylpiperazine, ${ }^{7 \mathrm{c}}$ was chosen for study: $\mathrm{H}_{2} \mathrm{MeTa}=\mathrm{C}$ $(\mathrm{Me}) \mathrm{Li}(\mathbf{5 k})$. Only the rotamer in which the methyl on the metal is syn to the Li substituent was studied. The calculated geometry of $\mathrm{H}_{2} \mathrm{MeTa}=\mathrm{C}(\mathrm{Me}) \mathrm{Li}$ is shown in Figure 6. As for the lithiomethylidene, $\mathbf{5 h}$, the eclipsed conformer of $\mathbf{5 k}$ is a minimum; replacing the $\mathrm{Li}$ in $\mathrm{H}_{2} \mathrm{MeTa}=\mathrm{C}(\mathrm{Me}) \mathrm{Li}$ with a hydrogen, 51, yields a transition state for the eclipsed conformer and a much longer $\mathrm{TaC}_{\alpha}$ bond. The $\mathrm{TaC}_{\alpha}$ distances in the lithiomethylidenes $\mathbf{5 h}$ and $\mathbf{5 k}$ are appreciably shorter than those found for the other $\mathrm{Ta}-$ alkylidenes, 1.81 and $1.82 \AA$.

The complex $\mathrm{H}_{3} \mathrm{Ta}=\mathrm{C}(\mathrm{OH})\left(\mathrm{NH}_{2}\right)(5 p)$ has a metal-carbon bond length which is appreciably longer than those in the other $\mathrm{Ta}$-alkylidenes, $2.05 \AA$. For comparison purposes, the $\mathrm{Ta}-\mathrm{C}$ bond distance in the singly bonded, methyl complex $\left[\mathrm{H}_{3} \mathrm{TaCH}_{3}\right]^{+}(\mathbf{5 q})$ is calculated to be $2.06 \AA$ while the triply bonded complex $\left[\mathrm{H}_{3} \mathrm{Ta} \equiv \mathrm{CH}\right]^{-}(\mathbf{5 r})$ has an equilibrium bond length of $1.80 \AA$. The $\mathrm{TaC}_{\alpha}$ bond lengths and force constants for $5 \mathbf{h}$ and $5 \mathbf{p}$ are close to the limiting triple- and single-bond values, respectively: see Figure 5 and Table II.

2. Electronic Structure of Substituted Alkylidenes. The $\mathrm{MC} / \mathrm{LMO} / \mathrm{CI}$ procedure has been described elsewhere ${ }^{4}$ and need only be briefly summarized here. The MC/LMO/CI procedure consists of three steps: In step 1, the canonical, RHF metal-carbon $\sigma, \pi, \pi^{*}$, and $\sigma^{*}$ molecular orbitals (MOs) are identified as the active space, and a four-orbital, four-electron FORS-MCSCF (full optimized reaction space-multiconfiguration self-consistent

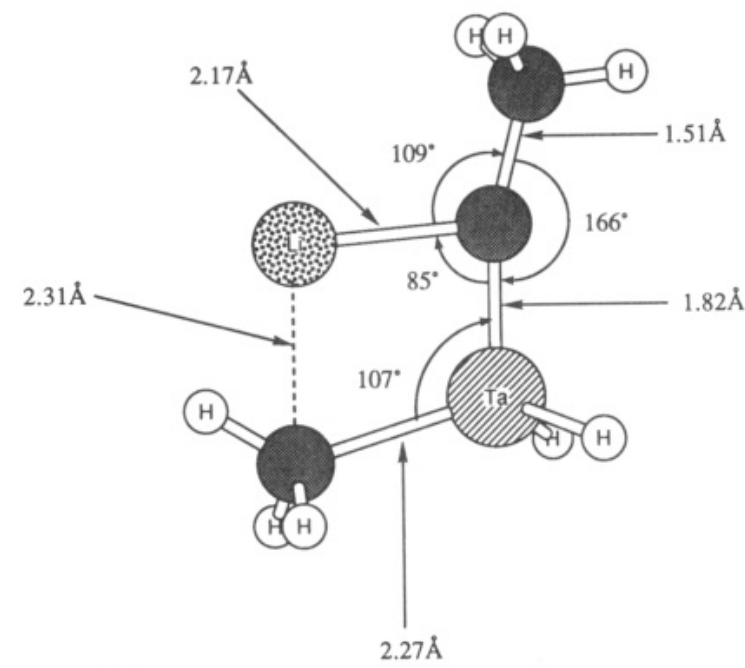

Figure 6. Minimum energy geometry of $\mathrm{H}_{2} \mathrm{MeTa}=\mathrm{C}(\mathrm{Me}) \mathrm{Li}$. The bond lengths are in angstroms, and the bond angles are in degrees.

field $^{15}$ ) calculation is carried out. The FORS-MCSCF method includes the effects of electron correlation by forming all possible configurations which can be constructed by distributing the four electrons in the $\sigma \pi \pi^{*} \sigma^{*}$ active space and optimizing the orbitals as well as the total (20 configuration) FORS-MCSCF wave function. In step 2, the MCSCF natural orbitals are localized using the Boys technique ${ }^{16}$ to yield "AO-like" MOs- $\sigma_{\mathrm{C}}, \pi_{\mathrm{C}}, \pi_{\mathrm{M}}$, and $\sigma_{\mathrm{M}}$. These "AO-like" MOs are predominantly $(>98 \%)$ located on either the metal (M) or carbon (C) end of the metal-carbon bond, based on a Mulliken population analysis. In step 3, configuration interaction (CI) with an active space comprised of the "AO-like" MOs is used to generate all (20 in total) possible resonance structures needed to describe the metal-carbon double bond.

Of the 20 configurations (19 spatial products with two spin products, IX and XI, for the |1111) configurations which are summed together), only a limited number are physically sensible. It seems logical to expect that those resonance structures which possess two electrons each in the $\sigma$ and $\pi$ manifolds will be the prime contributors. In this way the alkylidene avoids large

(15) Ruedenberg, K.; Schmidt, M. W.; Dombek, M. M.; Elbert, S. T. Chem. Phys. 1982, 71, 41, 51, 65.

(16) Foster, J. M.; Boys, S. F. Rev. Mod. Phys. 1960, 32, 300. 
Table III. Resonance Contributors for Ti-Alkylidenes ${ }^{a}$

\begin{tabular}{|c|c|c|c|c|c|}
\hline & & $\mathrm{H}_{2} \mathrm{Ti}=\mathrm{CH}_{2}$ & $\mathrm{H}_{2} \mathrm{Ti}=\mathrm{C}(\mathrm{H}) \mathrm{Cl}$ & $\mathrm{H}_{2} \mathrm{Ti}=\mathrm{CCl}_{2}$ & $\mathrm{Cl}_{2} \mathrm{Ti}=\mathrm{CH}_{2}$ \\
\hline I & $|2200\rangle^{b}$ & 0.160 & 0.145 & 0.139 & 0.126 \\
\hline III & |1201\} & 0.311 & 0.268 & 0.237 & 0.267 \\
\hline VI & $0202\rangle$ & 0.152 & 0.130 & 0.113 & 0.140 \\
\hline VII & $|2110\rangle$ & 0.602 & 0.625 & 0.648 & 0.581 \\
\hline IX & [1111) & 0.551 & 0.552 & 0.482 & 0.578 \\
\hline XI & $|1111\rangle$ & 0.247 & 0.244 & 0.354 & 0.254 \\
\hline XIV & $|0112\rangle$ & 0.162 & 0.161 & 0.161 & 0.178 \\
\hline XV & $|2020\rangle$ & 0.271 & 0.283 & 0.283 & 0.299 \\
\hline XVIII & |1021) & 0.160 & 0.164 & 0.162 & 0.184 \\
\hline $\mathrm{XX}$ & j0022> & 0.029 & 0.030 & 0.030 & 0.034 \\
\hline nucleophilic (\%) & & 48 & 48 & 50 & 42 \\
\hline neutral (\%) & & 46 & 46 & 45 & 51 \\
\hline \multirow[t]{2}{*}{ electrophilic (\%) } & & 5 & 5 & 5 & 7 \\
\hline & & $\mathrm{H}_{2} \mathrm{Ti}=\mathrm{C}(\mathrm{H}) \mathrm{Li}$ & $\mathrm{H}_{2} \mathrm{Ti}=\mathrm{C}(\mathrm{H}) \mathrm{Me}$ & $\mathrm{H}_{2} \mathrm{Ti}=\mathrm{C}(\mathrm{H}) \mathrm{SiH}_{3}$ & $\mathrm{H}_{2} \mathrm{Ti}=\mathrm{C}(\mathrm{H}) \mathrm{OH}$ \\
\hline I & $|2200\rangle^{b}$ & 0.131 & 0.150 & 0.187 & 0.049 \\
\hline III & |1201\} & 0.384 & 0.305 & 0.367 & 0.123 \\
\hline VI & j0202〉 & 0.224 & 0.152 & 0.174 & 0.068 \\
\hline VII & $|2110\rangle$ & 0.455 & 0.584 & 0.592 & 0.542 \\
\hline IX & |11111〉 & 0.600 & 0.561 & 0.529 & 0.491 \\
\hline XI & $|1111\rangle$ & 0.265 & 0.248 & 0.244 & 0.375 \\
\hline XIV & $|0112\rangle$ & 0.197 & 0.167 & 0.150 & 0.161 \\
\hline XV & $2020\rangle$ & 0.286 & 0.288 & 0.254 & 0.455 \\
\hline XVIII & $|1021\rangle$ & 0.198 & 0.176 & 0.146 & 0.255 \\
\hline $\mathrm{XX}$ & $|0022\rangle$ & 0.039 & 0.033 & 0.025 & 0.041 \\
\hline nucleophilic (\%) & & 37 & 46 & 52 & 31 \\
\hline neutral (\%) & & 56 & 48 & 43 & 59 \\
\hline electrophilic (\%) & & 8 & 6 & 4 & 27 \\
\hline
\end{tabular}

${ }^{a}$ The values in this table were calculated at the minima in Figure 1 using basis B (see text). ${ }^{b}$ The notation lijkl) denotes the occupation numbers of the AO-like MOs which comprise the configuration $\left|\sigma_{\mathrm{C}}{ }^{i} \pi_{\mathrm{C}} \pi_{\mathrm{M}}{ }^{k} \sigma_{\mathrm{M}}{ }^{i}\right\rangle$.

Table IV. Resonance Contributors for $\mathrm{Zr}$-Alkylidenes ${ }^{a}$

\begin{tabular}{|c|c|c|c|c|c|}
\hline & & $\mathrm{H}_{2} \mathrm{Zr}=\mathrm{CH}_{2}$ & $\mathrm{H}_{2} \mathrm{Zr}=\mathrm{C}(\mathrm{H}) \mathrm{Cl}$ & $\mathrm{H}_{2} \mathrm{Zr}=\mathrm{CCl}_{2}$ & $\mathrm{Cl}_{2} \mathrm{Zr}=\mathrm{CH}_{2}$ \\
\hline 1 & $|2200\rangle^{b}$ & 0.250 & 0.251 & 0.252 & 0.223 \\
\hline III & $|1201\rangle$ & 0.375 & 0.359 & 0.344 & 0.351 \\
\hline VI & |0202〉 & 0.177 & 0.167 & 0.157 & 0.175 \\
\hline VII & $|2110\rangle$ & 0.556 & 0.574 & 0.592 & 0.546 \\
\hline IX & $|1111\rangle$ & 0.518 & 0.516 & 0.512 & 0.534 \\
\hline $\mathrm{XI}$ & $11111\rangle$ & 0.244 & 0.240 & 0.234 & 0.251 \\
\hline XIV & $0112\rangle$ & 0.175 & 0.172 & 0.168 & 0.189 \\
\hline XV & $2020\rangle$ & 0.260 & 0.261 & 0.263 & 0.276 \\
\hline XVIII & $|1021\rangle$ & 0.169 & 0.166 & 0.163 & 0.189 \\
\hline $\mathrm{XX}$ & $|0022\rangle$ & 0.032 & 0.032 & 0.032 & 0.039 \\
\hline \multirow{4}{*}{$\begin{array}{l}\text { nucleophilic (\%) } \\
\text { neutral }(\%) \\
\text { electrophilic (\%) }\end{array}$} & & 51 & 52 & 53 & 47 \\
\hline & & 43 & 42 & 41 & 46 \\
\hline & & 6 & 6 & 6 & 7 \\
\hline & & $\mathrm{H}_{2} \mathrm{Zr}=\mathrm{C}(\mathrm{H}) \mathrm{Li}$ & $\mathrm{H}_{2} \mathrm{Zr}=\mathrm{C}(\mathrm{H}) \mathrm{Me}$ & $\mathrm{H}_{2} \mathrm{Zr}=\mathrm{C}(\mathrm{H}) \mathrm{SiH}_{3}$ & $\mathrm{H}_{2} \mathrm{Zr}=\mathrm{C}(\mathrm{H}) \mathrm{OH}$ \\
\hline I & $|2200\rangle^{b}$ & 0.204 & 0.235 & 0.281 & 0.189 \\
\hline III & $|1201\rangle$ & 0.405 & 0.367 & 0.410 & 0.298 \\
\hline VI & $0202\rangle$ & 0.217 & 0.178 & 0.187 & 0.146 \\
\hline VII & $|2110\rangle$ & 0.466 & 0.528 & 0.552 & 0.546 \\
\hline IX & $|1111\rangle$ & 0.557 & 0.528 & 0.498 & 0.539 \\
\hline XI & |11111) & 0.260 & 0.247 & 0.239 & 0.249 \\
\hline XIV & $|0112\rangle$ & 0.194 & 0.183 & 0.161 & 0.189 \\
\hline $\mathrm{XV}$ & $2020\rangle$ & 0.265 & 0.273 & 0.241 & 0.333 \\
\hline XVIII & j1021\} & 0.205 & 0.186 & 0.151 & 0.232 \\
\hline $\mathrm{XX}$ & j0022) & 0.036 & 0.037 & 0.027 & 0.049 \\
\hline nucleophilic (\%) & & 42 & 48 & 55 & 42 \\
\hline neutral (\%) & & 50 & 45 & 40 & 49 \\
\hline electrophilic (\%) & & 8 & 7 & 5 & 9 \\
\hline
\end{tabular}

${ }^{a}$ The values in the table were calculated at the minima in Figure 2 using basis B (see text). ${ }^{b}$ The notation $|i j k l\rangle$ denotes the occupation numbers of the AO-like MOs which comprise the configuration $\left|\sigma_{\mathrm{C}}{ }^{i} \pi_{\mathrm{C}}{ }^{j} \pi_{\mathrm{M}}{ }^{k} \sigma_{\mathrm{M}}{ }^{l}\right\rangle$.

contributions from configurations with weaker one- and threeelectron bonds. It is satisfying that the $\mathrm{MC} / \mathrm{LMO} / \mathrm{CI}$ scheme (Tables III-VII) predicts that only those configurations which conform to this chemical intuition make any appreciable contribution to the total wave functions. There are nine such "chemical" configurations, and as illustrated in Tables III-VII, these configurations account for nearly all (99-100\%) of the wave functions for the compounds considered here. The nine "chemical" configurations which describe the metal-carbon double bond are depicted schematically in Appendix I.

One other property, in addition to the weights, derived from the MC/LMO/CI procedure is of interest. The percentage contribution from nucleophilic, electrophilic, and neutral resonance structures can be obtained from the square of the coefficients of those resonance structures in which the formal charge on $\mathrm{C}_{\alpha}$ is negative, positive, and zero, respectively. Note that this refers to the metal-carbon bond and not the whole molecule. Thus, the nucleophilic resonance contributions come from configurations 
Table V. Resonance Contributors for Hf-Alkylidenes ${ }^{a}$

\begin{tabular}{|c|c|c|c|c|c|}
\hline & & $\mathrm{H}_{2} \mathrm{Hf}=\mathrm{CH}_{2}$ & $\mathrm{H}_{2} \mathrm{Hf}=\mathrm{C}(\mathrm{H}) \mathrm{Cl}$ & $\mathrm{H}_{2} \mathrm{Hf}=\mathrm{CCl}_{2}$ & $\mathrm{Cl}_{2} \mathrm{Hf}=\mathrm{CH}_{2}$ \\
\hline I & $|2200\rangle^{b}$ & 0.285 & 0.287 & 0.290 & 0.261 \\
\hline III & |1201\} & 0.388 & 0.378 & 0.368 & 0.369 \\
\hline VI & |0202\} & 0.176 & 0.169 & 0.163 & 0.173 \\
\hline VII & $|2110\rangle$ & 0.558 & 0.572 & 0.585 & 0.553 \\
\hline IX & (1111) & 0.498 & 0.497 & 0.494 & 0.513 \\
\hline XI & |1111) & 0.236 & 0.232 & 0.223 & 0.243 \\
\hline XIV & $0112\rangle$ & 0.168 & 0.167 & 0.164 & 0.180 \\
\hline$X V$ & $2020\rangle$ & 0.253 & 0.252 & 0.252 & 0.267 \\
\hline XVIII & 1021) & 0.164 & 0.160 & 0.157 & 0.180 \\
\hline $\mathrm{XX}$ & $10022\rangle$ & 0.031 & 0.031 & 0.030 & 0.036 \\
\hline nucleophilic (\%) & & 54 & 55 & 56 & 51 \\
\hline neutral (\%) & & 40 & 39 & 38 & 42 \\
\hline \multirow[t]{2}{*}{ electrophilic (\%) } & & 6 & 5 & 5 & 7 \\
\hline & & $\mathrm{H}_{2} \mathrm{Hf}=\mathrm{C}(\mathrm{H}) \mathrm{Li}$ & $\mathrm{H}_{2} \mathrm{Hf}=\mathrm{C}(\mathrm{H}) \mathrm{Me}$ & $\mathrm{H}_{2} \mathrm{Hf}=\mathrm{C}(\mathrm{H}) \mathrm{SiH}_{3}$ & $\mathrm{H}_{2} \mathrm{Hf}=\mathrm{C}(\mathrm{H}) \mathrm{OH}$ \\
\hline I & $|2200\rangle^{b}$ & 0.235 & 0.287 & 0.317 & 0.224 \\
\hline III & 1201) & 0.422 & 0.388 & 0.417 & 0.329 \\
\hline VI & |0202〉 & 0.215 & 0.179 & 0.181 & 0.158 \\
\hline VII & $|2110\rangle$ & 0.475 & 0.545 & 0.555 & 0.542 \\
\hline IX & |1111) & 0.536 & 0.509 & 0.479 & 0.525 \\
\hline $\mathrm{XI}$ & 11111) & 0.255 & 0.240 & 0.230 & 0.245 \\
\hline XIV & $0112\}$ & 0.183 & 0.177 & 0.155 & 0.189 \\
\hline XV & $2020\rangle$ & 0.261 & 0.265 & 0.236 & 0.314 \\
\hline XVIII & |1021) & 0.196 & 0.180 & 0.147 & 0.224 \\
\hline$X X$ & |0022) & 0.032 & 0.035 & 0.025 & 0.047 \\
\hline nucleophilic (\%) & & 46 & 52 & 58 & 45 \\
\hline neutral $(\%)$ & & 47 & 42 & 37 & 46 \\
\hline electrophilic (\%) & & 7 & 6 & 5 & 9 \\
\hline
\end{tabular}

${ }^{a}$ The values in the table were calculated at the minima in Figure 3 using Basis B (see text). ${ }^{b}$ The notation $|i j k l\rangle$ denotes the occupation numbers of the AO-like MOs which comprise the configuration $\left|\sigma_{\mathrm{C}}{ }^{i} \pi_{\mathrm{C}} \pi_{\mathrm{M}}{ }^{k} \sigma_{\mathrm{M}}{ }^{l}\right\rangle$.

Table VI. Resonance Contributors for Nb-Alkylidenes ${ }^{a}$

\begin{tabular}{|c|c|c|c|c|}
\hline & & $\mathrm{H}_{3} \mathrm{Nb}=\mathrm{CH}_{2}$ & $\mathrm{Cl}_{3} \mathrm{Nb}=\mathrm{CH}_{2}$ & $\mathrm{H}_{3} \mathrm{Nb}=\mathrm{CCl}_{2}$ \\
\hline I & $|2200\rangle^{b}$ & 0.192 & 0.160 & 0.187 \\
\hline III & |1201〉 & 0.342 & 0.311 & 0.306 \\
\hline VI & $|0202\rangle$ & 0.186 & 0.184 & 0.157 \\
\hline VII & $|2110\rangle$ & 0.513 & 0.490 & 0.553 \\
\hline IX & |1111) & 0.555 & 0.574 & 0.549 \\
\hline XI & $|1111\rangle$ & 0.257 & 0.267 & 0.248 \\
\hline XIV & $|0112\rangle$ & 0.210 & 0.234 & 0.196 \\
\hline $\mathrm{XV}$ & $2020\rangle$ & 0.285 & 0.296 & 0.303 \\
\hline XVIII & $|1021\rangle$ & 0.213 & 0.237 & 0.209 \\
\hline $\mathrm{XX}$ & $|0022\rangle$ & 0.047 & 0.057 & 0.045 \\
\hline nucleophilic (\%) & & 42 & 36 & 43 \\
\hline neutral $(\%)$ & & 49 & 52 & 48 \\
\hline \multirow[t]{2}{*}{ electrophilic (\%) } & & 9 & 11 & 8 \\
\hline & & $\mathrm{H}_{3} \mathrm{Nb}=\mathrm{C}(\mathrm{H}) \mathrm{Me}$ & $\mathrm{H}_{3} \mathrm{Nb}=\mathrm{C}(\mathrm{H}) \mathrm{OH}$ & $\mathrm{H}_{3} \mathrm{Nb}=\mathrm{C}(\mathrm{H}) \mathrm{SiH}_{3}$ \\
\hline I & $|2200\rangle^{b}$ & 0.177 & 0.134 & 0.214 \\
\hline III & $|1201\rangle$ & 0.331 & 0.252 & 0.377 \\
\hline VI & $10202\rangle$ & 0.185 & 0.138 & 0.201 \\
\hline VII & $2110\rangle$ & 0.496 & 0.497 & 0.508 \\
\hline IX & $11111\rangle$ & 0.563 & 0.561 & 0.542 \\
\hline XI & $|1111\rangle$ & 0.260 & 0.252 & 0.258 \\
\hline XIV & 0112) & 0.219 & 0.209 & 0.202 \\
\hline XV & $2020\rangle$ & 0.298 & 0.378 & 0.265 \\
\hline XVIII & |1021) & 0.233 & 0.287 & 0.196 \\
\hline $\mathrm{XX}$ & |0022) & 0.054 & 0.064 & 0.042 \\
\hline nucleophilic (\%) & & 39 & 33 & 45 \\
\hline neutral $(\%)$ & & 51 & 54 & 47 \\
\hline electrophilic (\%) & & 11 & 13 & 8 \\
\hline
\end{tabular}

${ }^{a}$ The values in the table were calculated at the minima displayed in Figure 4 using basis $B$ (see text). The calculated weights are in fractional terms, and the sum of their squares for any complex is unity. ${ }^{b}$ The notation for the configuration $|i j k l\rangle$ denotes the occupation numbers of the AO-like MOs which comprise the configuration $\left|\sigma_{C}{ }^{i} \pi_{C}^{j} \pi_{M}{ }^{k} \sigma_{M}{ }^{l}\right\rangle$.

I, III, and VII. The neutral resonance contributions arise from VI, IX, XI, and XV. The electrophilic resonance structures are XIV, XVIII, and XX.

a. Group IVB Alkylidenes. The MCSCF calculations using the canonical RHF MOs as a starting basis reveal that these complexes are well described at the Hartree-Fock level. In all cases studied, the HF configuration, $\sigma_{M C}{ }^{2} \pi_{M C}{ }^{2}$, possesses the largest coefficient ( $\approx 93 \%$ of the MCSCF wave function). As a comparison, the $\sigma_{C C}{ }^{2} \pi_{C C}{ }^{2}$ configuration accounts for roughly $95 \%$ of the MCSCF wave function of ethylene (with the 3-21G(d) basis set) at its equilibrium geometry. In all cases the HOMO is the $\pi_{M C}$ bonding MO. The $\sigma_{M C}$ and $\pi_{M C}$ MOs are polarized toward the $\alpha$-carbon, particularly the former. Given the nucleophilicity of $\mathrm{C}_{\alpha}$ in Schrock-type alkylidenes, this is to be expected. Localization of the canonical RHF MOs of the both the "normal" and "distorted" $\left(\mathrm{H}_{2} \mathrm{M}=\mathrm{C}(\mathrm{H}) \mathrm{Li}\right.$ and $\left.\mathrm{H}_{2} \mathrm{M}=\mathrm{C}(\mathrm{H}) \mathrm{Me}\right)$ alkylidenes 
Table VII. Resonance Contributors for Ta-Alkylidenes ${ }^{a}$

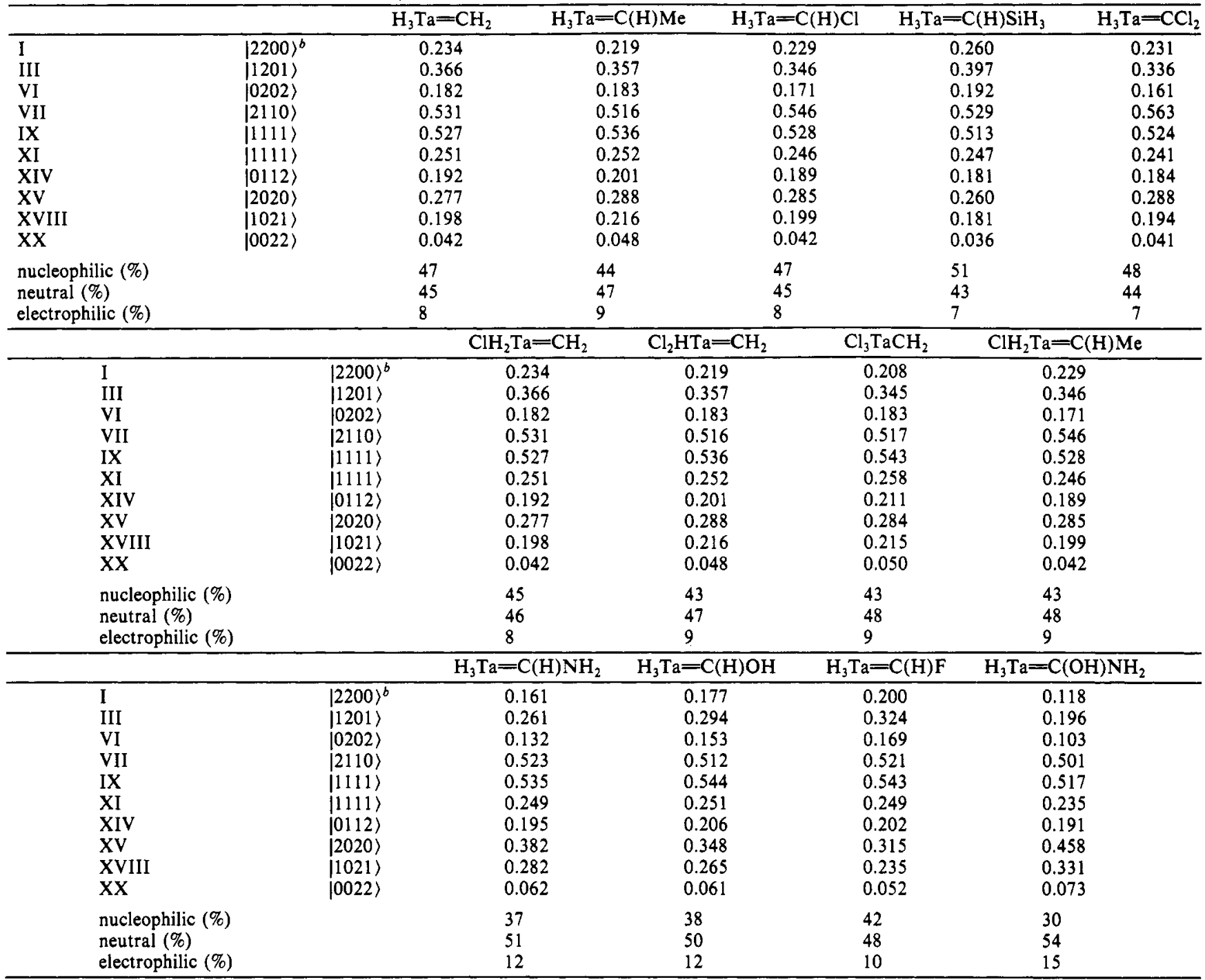

${ }^{a}$ The values in the table were calculated at the minima in Figure 5 using basis $B$ (see text).

yields the typical, ethylene Lewis structure. There are six localized MOs (LMOs) schematically depicted as follows.

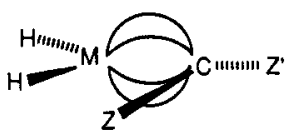

Based on the LMO analysis, there is no interaction between the substituent $(Z)$ which is close to the metal and either $M$ or $H$ and there is no suggestion of a metal-carbon triple bond in the distorted group IVB alkylidenes. The $\mathrm{M}=\mathrm{C}$ bonding region is occupied by two "bent" or banana bonds upon Boys localization in all of the group IVB alkylidenes studied, except for $\mathrm{H}_{2} \mathrm{Ti}=\mathrm{C}(\mathrm{H}) \mathrm{OH}$ (1h). For $1 \mathrm{~h}$ the metal-carbon bonding region is occupied by distinct $\sigma$ and $\pi$ orbitals.

The relative weights of the resonance structures, calculated using the $\mathrm{MC} / \mathrm{LMO} / \mathrm{CI}$ procedure, which describe the metal-carbon double bond linkage for the group IVB alkylidenes are listed in Tables III-V. As for the unsubstituted case $\left(\mathrm{H}_{2} \mathrm{M}=\mathrm{CH}_{2}{ }^{4 a}\right)$ the same configurations are the prime resonance contributors for all substituted cases, although their relative amounts vary with the substituents and ligands. The resonance structures which make the largest contribution (and account for roughly 95\% of the total) to the ground states are similar to those shown in the Introduction. The group IVB alkylidenes which differ the most with respect to the relative amounts of nucleophilic and neutral resonance structure contributions are the lithiomethylidenes and hydroxymethylidenes. As noted previously, the former have shorter
$\mathrm{M}=\mathrm{C}_{\alpha}$ bonds while the latter possess longer $\mathrm{M}=\mathrm{C}_{\alpha}$ bonds than the rest of the group IVB alkylidenes. For both the hydroxy- and lithiomethylidenes the nucleophilic and neutral resonance structures make comparable contributions to the ground-state wave function; for the remaining species the nucleophilic structures typically outweigh the neutral resonance structures by $8 \%$ or more. An exception to this trend is Hf, for which the nucleophilic resonance structures seem to be more dominant. In general, the electrophilic resonance structures make much smaller contributions.

When analogous (i.e., same ligands and substituents) group IVB alkylidenes are compared, two trends become apparent (Tables III-V): The first trend is the steady increase in the percentage of nucleophilic resonance structures as one goes toward the heavier elements in group IVB. The second trend is the decrease in neutral resonance structures upon going from $\mathrm{Ti}$ to $\mathrm{Zr}$ to $\mathrm{Hf}$. The average contribution from electrophilic resonance structures remains fairly constant (other than $\mathrm{H}_{2} \mathrm{Ti}=\mathrm{C}(\mathrm{H}) \mathrm{OH}$ ) at $\approx 6 \pm 1 \%$. These two trends taken together suggest that the Hf-alkylidenes will be more nucleophilic, all else being equal, than their $\mathrm{Zr}$ and $\mathrm{Ti}$ counterparts. The metal becomes more electrophilic or electron deficient as one proceeds from $\mathrm{Ti}$ to $\mathrm{Hf}$. The metal-carbon double bond is more polarized in $\mathrm{Hf}$-alkylidenes than in $\mathrm{Ti}$-alkylidenes. A detailed analysis of the wave functions indicates that this greater polarization is due to greater polarization of the metal-carbon $\pi$ bond toward $\mathrm{C}_{\alpha}$, while the $\sigma$ bond remains constant. Experimental and theoretical studies ${ }^{18}$ on olefin metathesis catalysts indicate that increased polarization of the metal (i.e., a more electron-deficient 
metal and a more electron-rich $\alpha$-carbon) correlates with greater reactivity in the olefin metathesis reaction. The present results suggest that $\mathrm{Hf}$-alkylidenes would be more reactive for the olefin metathesis reaction than $\mathrm{Ti}-$ and $\mathrm{Z}_{\mathrm{I}}$-alkylidenes.

b. Group VB Alkylidenes. The group VB alkylidenes represent a large portion of the high-valent, transition-metal alkylidenes which have been characterized to date. ${ }^{2,3 c, 7,8}$ Thus, greater attention has been focused upon them in this study, in particular tantalum. The substituents that were studied can be grouped into three classes: good $\pi$ donors, intermediate $\pi$ donors, and poor $\pi$ donors. The typical Schrock-type carbene substituents $(\mathrm{H}$, alkyl, silyl) are poor $\pi$ donors. Halocarbenes have been considered as intermediate between the good $\pi$-donor substituents of Fischer-type carbenes and the poor $\pi$-donor substituents of Schrock-type carbenes. ${ }^{17}$ Given the interesting results that were seen for the group IVB hydroxymethylidenes, it was decided to further study Ta-alkylidenes with substituents more commonly associated with Fischer-type carbenes, i.e., $\mathrm{H}_{3} \mathrm{Ta}=\mathrm{C}(\mathrm{H}) \mathrm{OH}(5 \mathrm{~m}), \mathrm{H}_{3} \mathrm{Ta}=\mathrm{C}(\mathrm{H}$ $\mathrm{NH}_{2}(5 \mathrm{o})$, and $\mathrm{H}_{3} \mathrm{Ta}=\mathrm{C}(\mathrm{OH}) \mathrm{NH}_{2}(\mathbf{5 p})$.

Group VB alkylidenes are also described well at the HartreeFock level; the HF configuration $\sigma_{M C}{ }^{2} \pi_{M C}{ }^{2}$ accounts for $94 \%$ of the MCSCF wave function. The $\sigma_{\mathrm{MC}}$ is polarized toward the $\mathrm{C}_{\alpha}$ to a similar extent for the group IVB and VB complexes, although the $\pi_{\mathrm{MC}}$ is slightly less polarized toward $\mathrm{C}_{\alpha}$ for the group VB alkylidenes. As for the group IVB complexes, the $\pi_{M C}$ orbital is the HOMO.

In almost all cases localizing the canonical RHF MOs yields LMOs in accord with the simple Lewis structure (A). The $\mathrm{TaC}_{\alpha}$

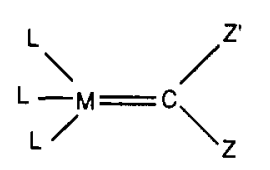

A

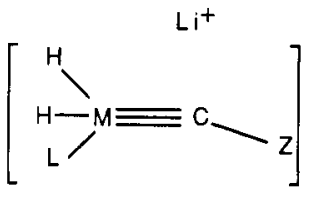

B bonding region is occupied by two "bent" bonds. The cases which are different are the lithium-substituted alkylidenes $(\mathbf{4 h}, \mathbf{5 h}, \mathbf{5 k})$ and $\mathrm{H}_{3} \mathrm{Ta}=\mathrm{C}(\mathrm{OH}) \mathrm{NH}_{2}(\mathbf{5 p})$. Localizing the canonical RHF MOs of $\mathrm{H}_{2} \mathrm{LM}=\mathrm{C}(\mathrm{Li}) \mathrm{Z}(\mathrm{M}=\mathrm{Ta}, \mathrm{L}=\mathrm{Z}=\mathrm{H}(\mathbf{5 h}) ; \mathrm{M}=\mathrm{Ta}$, $\mathrm{L}=\mathrm{Z}=\mathrm{Me}(5 \mathrm{k}) ; \mathrm{M}=\mathrm{Nb}, \mathrm{L}=\mathrm{Z}=\mathrm{H}(\mathbf{4 h})$ ) yields the following seven LMOs: two $\sigma_{\mathrm{MH}}, \sigma_{\mathrm{ML}}, \sigma_{\mathrm{CZ}}$, and three $\tau_{\mathrm{MC}}$. Unlike the group IVB analogues, a $\mathrm{MC}_{\alpha}$ triple bond and no $\mathrm{C}_{\alpha}-\mathrm{Li}$ bond is found! To be sure, the $\mathrm{Ta}-\mathrm{C}_{\alpha} \tau$ (bent) bonds contain a small amount of $\mathrm{Li}$ character, $\approx 8 \%$, but a Lewis structure like $\mathrm{B}$ is implied. The significantly higher $\mathrm{TaC}_{\alpha}$ force constants and shorter $\mathrm{TaC}_{\alpha}$ bond lengths for $\mathbf{4 h}, \mathbf{5 h}$, and $\mathbf{5 k}$ support a triple-bond description, (Table II). This description is also supported by the experimental evidence of Shrock and Guggenberger ${ }^{7 \mathrm{c}}$ for $\left(\mathrm{Me}_{3} \mathrm{CCH}_{2}\right)_{3} \mathrm{Ta}\left(\mathrm{C}\left(\mathrm{Li} N, N^{\prime}\right.\right.$. dimethylpiperazine) $\mathrm{CMe}_{3}$ ) which shows a very short $\mathrm{TaC}_{\alpha}$ bond length, a $\mathrm{Ta}-\mathrm{C}_{\alpha}-\mathrm{C}_{\beta}$ angle of $165^{\circ}$, and conductivity in THF solutions of this complex. The lithium atoms in the lithiumsubstituted, Ta-alkylidenes have a higher positive charge (calculated from the Mulliken population analysis), $\approx+0.50$, when compared to the group IVB lithiomethylidenes $(\approx+0.33)$. For $\mathrm{H}_{3} \mathrm{Ta}=\mathrm{C}(\mathrm{OH}) \mathrm{NH}_{2}(5 p)$ distinct $\sigma$ - and $\pi$-bonding MOs rather than bent $\mathrm{LMOs}$ are obtained in the $\mathrm{TaC}_{\alpha}$ bonding region. With respect to Boys localization, $\mathrm{H}_{3} \mathrm{Ta}=\mathrm{C}(\mathrm{OH}) \mathrm{NH}_{2}$ resembles the Fischer-type carbenes: Localized MO studies $^{4,19}$ indicate that Fischer-type carbenes yield separate $\sigma$ and $\pi$ MOs and Schrock-type carbenes yield two bent (or $\tau$ ) bonds.

Despite changes in the ligands and substituents, the nine "chemical" configurations describe the metal-carbon double bond very well. For poor $\left(\mathrm{H}, \mathrm{Me}, \mathrm{SiH}_{3}\right)$, intermediate $(\mathrm{Cl}, \mathrm{F})$, and good $\left(\mathrm{OH}, \mathrm{NH}_{2}\right) \pi$ donors the five prime resonance contributors de-

(17) Brothers, P. J.; Roper, W. R. Chem. Rev. 1988, 88, 1293. Gallop, M. A.; Roper, W. R. Adv. Organomet. Chem. 1986, 25, 121

(18) A theoretical analysis of models for olefin metathesis catalysts is presented in ref 5 along with the pertinent experimental references. 993

(19) Marynick, D. S.; Kirkpatrick, C. M. J. Am. Chem. Soc. 1985, 107, picted in the Introduction (IX and XI, III, XV, I and VII) account for $84-91 \%$ of the ground-state wave functions. As for the group IVB case, and as to be expected from their reactivity, the group VB alkylidenes are dominated $(\approx 90 \%)$ by nucleophilic and neutral resonance structures. A comparison of Tables VI and VII shows a larger percentage of nucleophilic resonance structures $($ by $\approx 5 \%$ ) for $\mathrm{Ta}$ - versus analogous $\mathrm{Nb}$-alkylidenes. As outlined above for the group IVB alkylidenes, this suggests greater nucleophilicity for Ta-alkylidenes when compared to their $\mathrm{Nb}$ analogues. The electrophilic resonance structures make their largest contributions in those Ta-alkylidenes with good $\pi$-donor substituents, $\mathrm{NH}_{2}$ and $\mathrm{OH}$. These changes in the electronic structure of the $\pi$-donorsubstituted Ta-alkylidenes would be expected to make $\mathrm{C}_{\alpha}$ increasingly electrophilic (or perhaps more correctly, less nucleophilic). The bonding in these Ta-alkylidenes is moved in the direction one would expect for carbene complexes which typically possess $\mathrm{OR}$ and $\mathrm{NR}_{2}$ ligands, i.e., Fischer-type carbenes. This suggests that the carbene substituents may play a more prominent role in determining the differences in the reactivity of the Fischer and Schrock carbenes than is commonly suspected.

The intermediate $(\mathrm{Cl}, \mathrm{F})$ and good $\left(\mathrm{NH}_{2}, \mathrm{OH}\right) \pi$ donors exert the largest influence on the metal-carbon $\pi$ bond. These substituents are, of course, electronegative and make the metal-carbon $\sigma$ bond more dative. However, their biggest effect is on the metal-carbon $\pi$ bond. As Roper has pointed out, ${ }^{17}$ good $\pi$-donor substituents will lower the need for metal to ligand $\pi$ back-bonding. The $\mathrm{MC} / \mathrm{LMO} / \mathrm{CI}$ procedure allows for a direct measurement of the extent to which such $\pi$ back-bonding occurs. The percentage of resonance structures with two electrons in the $\mathrm{C}_{\alpha} \pi$ "AO-like" MO (i.e., $|i 20 j\rangle \pi$-back-bonding configurations where $i, j=0-2$ and $i+j=2$ ) should decrease relative to $5 \mathrm{a}$ for Ta-alkylidenes with intermediate $\pi$ donors and to an even greater extent for Ta-alkylidenes with good $\pi$ donors. An examination of the data in Table VII supports this conclusion. The extent to which $|i 02 j\rangle$ configurations are present can be interpreted as a measure of the $\pi$-donor ability of the substituent-as the amount of $|i 02 j\rangle$ increases, the $\pi$-donor ability of the substituent increases. Using this criterion, a $\pi$-donor order for the Ta-alkylidenes is predicted: $\mathrm{NH}_{2}>\mathrm{OH}>\mathrm{F}>\mathrm{Cl}$. A further supposition that could be made pertains to the large $\mathrm{M}=\mathrm{C}-\mathrm{Z}$ angle. Since $\pi$ donors increase the percentage of $|i 02 j\rangle$ structures and the $\pi$ donor itself possesses a filled $\pi$-symmetry $\mathrm{MO}$, one can envision the large $\mathrm{M}=\mathrm{C}-\mathrm{Z}$ angles arising from a desire to minimize repulsion between electron pairs on the termini ( $M$ and $Z$ ). The simple picture assumes that the other group ( $\left.Z^{\prime}\right)$ attached to $C_{\alpha}$ is not a $\pi$ donor. If $Z$ and $Z^{\prime}$ are both $\pi$ donors, then increasing the $\mathrm{M}=\mathrm{C}-\mathrm{Z}$ angle to reduce repulsion between $M$ and $Z$ would cause increased repulsion between $Z^{\prime}$ and $M$ (assuming $Z-C-Z^{\prime}$ remains fairly constant). Reducing the repulsion between the electron pairs on the $\pi$ donors and $\mathrm{M}$ could be accomplished by lengthening the $\mathrm{TaC}_{\alpha}$ bond. This may explain the unusually long bond length in $\mathrm{H}_{3} \mathrm{Ta}=\mathrm{C}(\mathrm{OH}) \mathrm{NH}_{2}$ (5p).

It is possible to extend the MC/LMO/CI method to metalcarbon triple bonds, i.e., carbyne or alkylidynes; Li-substituted "alkylidenes" provide an excellent bridge between the alkylidenes and alkylidynes. The model alkylidyne chosen is that which one would obtain by taking the Ta-lithiomethylidene, $5 \mathrm{~h}$, to the extreme in which it seems to be heading $-\left[\mathrm{H}_{3} \mathrm{Ta} \equiv \mathrm{CH}\right]^{-}(5 \mathrm{r})$. Whereas 20 configurations are needed to fully describe four electrons in four orbitals, 175 configurations are needed to describe six electrons in six orbitals $\left(\sigma_{\mathrm{MC}}{ }^{2} \pi_{\mathrm{MC}}(1)^{2} \pi_{\mathrm{MC}}(2)^{2} \pi_{\mathrm{MC}}{ }^{*}(2)^{0}\right.$ $\left.\pi_{\mathrm{MC}}{ }^{*}(1)^{0}\left(\sigma_{\mathrm{MC}}\right)^{0}\right)$. As noted for the alkylidenes, those configurations with two electrons each in the various $\sigma$ and $\pi$ manifolds account for over $99 \%$ of the ground-state wave function. For the alkylidynes there are 37 configurations (27 spatial products) which satisfy this condition. These are depicted in Appendix I. An examination of the calculated MC/LMO/CI properties shows 5h and $5 r$ to be quite similar. The same configurations make similar (within $2 \%$ ) contributions. The lithiomethylidene is slightly more polarized toward the $C$ end than the carbyne: $\sigma_{C}{ }^{1.34} \pi_{C}(1)^{1.18}$ $\pi_{\mathrm{C}}(2)^{1.15} \pi_{\mathrm{M}}(2)^{0.85} \pi_{\mathrm{M}}(1)^{0.82} \sigma_{\mathrm{M}}{ }^{0.64}$ for $5 \mathbf{h}$ and $\sigma_{\mathrm{C}}{ }^{1.35} \pi_{\mathrm{C}}(1)^{1.12}$ $\pi_{C}(2)^{1.12} \pi_{M}(2)^{0.88} \pi_{M}(1)^{0.88} \sigma_{M}{ }^{0.65}$ for $5 \mathbf{r} .^{20}$ The greater polar- 
Chart I. Prime Resonance Contributors for Metal-Carbon Double, Triple, and Single Bonds

\begin{tabular}{|c|c|c|c|c|c|}
\hline$M=C$ & $12200>$ & $M=C$ & $12110\rangle$ & $M \rightleftharpoons C$ & $2020>$ \\
\hline$M=C$ & $|120|>$ & $\mathrm{M}=\mathrm{C}$ & $11111>\times 2$ & $\mathrm{M} \Rightarrow \mathrm{C}$ & 11021> \\
\hline $\mathrm{M}=\mathrm{C}$ & 10202> & $M=C$ & $10112>$ & $M \Rightarrow C$ & $10022>$ \\
\hline & & $M \neq C$ & $1222000>$ & & \\
\hline $\mathrm{M} \equiv \mathrm{C}$ & $1122001\rangle$ & $\mathrm{M} \rightleftharpoons \mathrm{C}$ & $1212010>$ & $\mathrm{M} \equiv \mathrm{C}$ & $1221100>$ \\
\hline $\mathrm{M} \equiv \mathrm{C}$ & $1211110>\times 2$ & $\mathrm{M} \rightleftharpoons \mathrm{C}$ & $1121101>\times 2$ & $M \doteq C$ & $11: 2011>\times 2$ \\
\hline$M \triangleq C$ & $1022002>$ & $\mathrm{M}=\mathrm{C}$ & $1202020\rangle$ & $\mathrm{M} \equiv \mathrm{C}$ & $1220200>$ \\
\hline & & $\mathrm{M} \equiv \mathrm{C}$ & $\mid 111111>\times 5$ & & \\
\hline $\mathrm{M} \equiv \mathrm{C}$ & $1102021 \mathrm{~s}$ & $\mathrm{M} \equiv \mathrm{C}$ & $012012>$ & $M \rightleftharpoons C$ & $1021102>$ \\
\hline $\mathrm{M} \rightleftharpoons \mathrm{C}$ & $1120201>$ & $\mathrm{M} \equiv \mathrm{C}$ & $1210210>$ & $M \equiv C$ & $201120>$ \\
\hline$M \equiv C$ & $1200220>$ & $\mathrm{M} \rightleftarrows \mathrm{C}$ & 1020202> & $\mathrm{M} \Longrightarrow \mathrm{C}$ & $1002022>$ \\
\hline $\mathrm{M} \equiv \mathrm{C}$ & $1011112>\times 2$ & $M \equiv C$ & $1101121>\times 2$ & $\mathrm{M} \equiv \mathrm{C}$ & $\mid 110211>$ \\
\hline $\mathrm{M} \equiv \mathrm{C}$ & $|100221\rangle$ & $\mathrm{M} \equiv \mathrm{C}$ & $1010212>$ & $\mathrm{M} \equiv \mathrm{C}$ & $1001122>$ \\
\hline & & $\mathrm{M} \equiv \mathrm{C}$ & $1000222>$ & & \\
\hline
\end{tabular}

ization toward $\mathrm{C}_{\alpha}$ probably results from the positive counterion in $\mathbf{5 h}$.

\section{Summary}

The MC/LMO/CI (multiconfugration/localized molecular orbital/configuration interaction) method was employed to analyze the electronic structure of alkylidene complexes. The most relevant conclusion is that the intrinsic nature of the metal-carbon double bond can only be changed within certain limits by modification of the electronegativity of the ligands (L) and substituents $(Z)$. In other words, the $\mathrm{Ta}=\mathrm{C}$ bond in $\mathrm{H}_{3} \mathrm{TaCH}_{2}$ is very similar to that in $\mathrm{H}_{3} \mathrm{TaCCl}_{2}$ and $\mathrm{Cl}_{3} \mathrm{TaCH}_{2}$. The calculations show that the electronic structure of the alkylidene does change in the directions expected for these alterations. Although beyond the limits of computational tractability, these trends are expected to be seen in experimentally characterized analogues with more ligands and substituents, e.g., $C p$ and neopentyl.

Significant changes in the electronic structure can be effected in three ways.

(1) Introduction of a highly electropositive substituent: A localized molecular orbital study of $\mathrm{H}_{3} \mathrm{TaC}(\mathrm{H}) \mathrm{Li}$ and $\mathrm{H}_{2} \mathrm{MeTaC}(\mathrm{Me}) \mathrm{Li}$, models of the complex $\left(\mathrm{Me}_{3} \mathrm{CCH}_{2}\right)_{3} \mathrm{TaC}$ $\left(\mathrm{CMe}_{3}\right) \mathrm{Li}$, ${ }^{\text {jc }}$ indicates a metal-carbon triple bond is present. Comparison of the bonding in the alkylidyne model $\mathrm{H}_{3} \mathrm{TaCH}^{-}$with $\mathrm{H}_{3} \mathrm{TaC}(\mathrm{H}) \mathrm{Li}$ shows them to be quite similar.

(2) A change in the central metal atom: The $\mathrm{MC} / \mathrm{LMO} / \mathrm{CI}$ results predict an increase in the nucleophilic character for alkylidenes in which the heaviest member of group IVB (Hf) and group VB (Ta) is the transition metal. Previous experimental and theoretical work ${ }^{18}$ suggests that greater polarization of the metal-carbon bond toward the $\alpha$-carbon $\left(\mathrm{M}^{\delta+}=\mathrm{C}^{\delta-}\right)$ in olefin

(20) The labels $\pi(1)$ and $\pi(2)$ refer to the in-plane and out-of-plane $\pi$ orbitals for $\mathrm{H}_{3} \mathrm{TaC}(\mathrm{H}) \mathrm{Li}$. The plane is that defined by the $\mathrm{Ta}, \mathrm{C}_{\alpha}$, and $\mathrm{Li}$. For the $C_{3 v}$ alkylidyne, $\mathrm{H}_{3} \mathrm{TaCH}^{+}, \pi(1)$ and $\pi(2)$ are equivalent since the $\pi$ MOs subtend the degenerate e irreducible representation. metathesis catalyst models correlates with greater reactivity. Our results suggest that the highest reactivity for group IVB and group VB could be obtained through the use of $\mathrm{Hf}-$ and Ta-alkylidenes, respectively.

(3) The use of $\pi$-donor substituents: Larger changes are observed when $\mathrm{Z}$ is a good $\pi$ donor (e.g., $\mathrm{NH}_{2}$ or $\mathrm{OH}$ ) than when $\mathrm{Z}$ is an intermediate $\pi$ donor (e.g., $\mathrm{Cl}$ or $\mathrm{F}$ ). The larger than typical $\left(>120^{\circ}\right) \mathrm{M}=\mathrm{C}-\mathrm{Z}$ angle for complexes of the type $\mathrm{H}_{3} \mathrm{TaC}(\mathrm{H}) \mathrm{Z}$ were observed and explained in terms of increased repulsion between the $\pi$-electron pairs on the termini of the three-center system.

The introduction of $\pi$-donor substituents on $\mathrm{C}_{\alpha}$ increases the percentage of electrophilic resonance structures. Thus, high-valent Schrock-type carbenes with $\pi$-donor substituents might be expected to display chemistry more commonly associated with Fischer-type carbenes, i.e., an electrophilic $\alpha$-carbon. This raises a question as to the role of the alkylidene substituents in determining the reactivity of the two classes of carbene complexes. To our knowledge, no Ta-alkyidene with a $\pi$-donor ligand has been synthesized and characterized. ${ }^{21}$ Our calculations indicate that such a molecule would exhibit interesting chemical and structural properties.

Acknowledgment. This work was supported in part by grants from the National Science Foundation (CHE89-11911) and the Air Force Office of Scientific Research (90-0052). The calculations described herein were carried out on a DECstation 3100 (funded by a grant from the National Science Foundation), an RS-6000 (funded by NSF Grant CHE90-05527), and the North Dakota State University IBM 3090-200E (purchased in part by a joint study agreement with IBM). We thank Drs. Walter Stevens, Morris Krauss, and Paul Jasien (all of NIST) and Harold Basch (Department of Chemistry, Bar Ilan University) for providing us with their ECPs prior to publication and Prof. Richard R. Schrock and Dr. Robert Toreki (Department of Chemistry, MIT) for communicating their results with us prior to publication.

\section{Appendix I}

The major resonance structures which are needed to describe the metal-carbon double, triple, and single bonds are depicted in Chart I using $|i j k l\rangle$ notation. As before, straight lines and arrows represent covalent and dative interactions, respectively. The $\sigma$ bond is represented by the lowest of the lines (or arrows); the other two lines (or arrows) portray the bonding in the $\pi$ bonds. The notation $(\times 2)$ and $(\times 5)$, which appear to the right of the configuration, signifies the number of spin products which have the spatial configuration shown. For configurations with two covalent bonds there are two spin products which give rise to a singlet wave function: $\alpha \beta \alpha \beta$ and $\alpha \alpha \beta \beta$. For the configuration with three covalent bonds there are five spin products giving rise to a singlet wave function: $\alpha \alpha \alpha \beta \beta \beta, \alpha \alpha \beta \beta \alpha \beta, \alpha \beta \alpha \alpha \beta \beta, \alpha \alpha \beta \alpha \beta \beta$, and $\alpha \beta \alpha \beta \alpha \beta$. The three possible resonance structures for a metal-carbon single bond are also shown.

Registry No. 1a, 78499-81-7; 1b, 137744-09-3; 1c, 137744-10-6; 1d, 79899-81-3; 1e, 83876-45-3; 1f, 83876-41-9; 1g, 137744-11-7; lb, 137744-12-8; 2a, 85028-91-7; 2b, 137744-13-9; 2c, 137744-14-0; 2d, 137744-15-1; 2e, 137744-16-2; 2f, 137744-17-3; 2g, 137744-18-4; 2h, 137744-19-5; 3a, 137744-20-8; 3b, 137744-21-9; 3c, 137744-22-0; 3d, 137744-23-1; 3e, 137744-24-2; 3f, 137744-25-3; 3g, 137744-26-4; 3h, 137744-27-5; 4a, 137744-28-6; 4d, 137744-29-7; 4e, 137744-30-0; 4g, 137744-31-1; 4h, 137744-32-2; 4i, 137744-34-4; 4m, 137744-33-3; 5a, 137744-35-5; 5b, 137744-36-6; 5c, 137744-37-7; 5d, 137744-38-8; 5e, 137744-39-9; 5f, 137744-40-2; 5g, 137744-41-3; 5h, 137744-42-4; 5i, $137744-43-5 ; 5 j, 137744-44-6 ; 5 k, 137744-45-7 ; 51,137744-46-8 ; 5 m$, 137744-47-9; 5n, 137744-48-0; 5o, 137744-49-1; 5p, 137744-50-4; 5q, $137744-51-5 ; 5 r, 137768-19-5$

(21) Toreki and Schrock have recently synthesized some hetero-substituted, $\mathrm{Re}$-alkylidene complexes and reported interesting reactivity for these. 